This is an electronic reprint of the original article. This reprint may differ from the original in pagination and typographic detail.

Author(s): Rojas Zuluaga, Bibiana

Title: Behavioural, ecological, and evolutionary aspects of diversity in frog colour patterns

Year: $\quad 2017$

Version:

Please cite the original version:

Rojas Zuluaga, B. (2017). Behavioural, ecological, and evolutionary aspects of diversity in frog colour patterns. Biological Reviews, 92(2), 1059-1080.

https://doi.org/10.1111/brv.12269

All material supplied via JYX is protected by copyright and other intellectual property rights, and duplication or sale of all or part of any of the repository collections is not permitted, except that material may be duplicated by you for your research use or educational purposes in electronic or print form. You must obtain permission for any other use. Electronic or print copies may not be offered, whether for sale or otherwise to anyone who is not an authorised user. 
If you prefer having the published PDF please send me a message here (or an email: bibianaDOTrojasATjyuDOTfi)

BIOLOGICAL
REVIEWS

\section{Behavioural, ecological, and evolutionary aspects of diversity in frog colour patterns}

\begin{tabular}{|r|l|}
\hline Journal: & Biological Reviews \\
\hline Manuscript ID & BRV-01-2015-0009.R3 \\
\hline Manuscript Type: & Original Article \\
\hline Date Submitted by the Author: & 26-Feb-2016 \\
\hline Keywlete List of Authors: & Rojas, Bibiana; University of Jyväskylä, Biology and Environmental Science \\
\hline & $\begin{array}{l}\text { colouration, anti-predator strategies, conflict resolution, visual } \\
\text { communication, sexual selection, space use }\end{array}$ \\
\hline
\end{tabular}

SCHOLARONE ${ }^{\text {m }}$

Manuscripts 
1 Behavioural, ecological, and evolutionary aspects of diversity

\section{2 in frog colour patterns}

3

4 Bibiana Rojas*

5

6 University of Jyvaskyla, Centre of Excellence in Biological Interactions, Department of

7 Biology and Environmental Sciences, PO Box 35, FI 40001, Jyväskylä, Finland

8

$9 \quad{ }^{*}$ E-mail: bibiana.rojas@jyu.fi; Tel.: +358 408054622.

11 ABSTRACT

12 The role of colours and colour patterns in behavioural ecology has been extensively

13 studied in a variety of contexts and taxa, while almost overlooked in many others. For

14 decades anurans have been the focus of research on acoustic signalling due to the

15 prominence of vocalisations in their communication. Much less attention has been paid

16 to the enormous diversity of colours, colour patterns, and other types of putative visual

17 signals exhibited by frogs. With the exception of some anecdotal observations and

18 studies, the link between colour patterns and the behavioural and evolutionary ecology

19 of anurans had not been addressed until approximately two decades ago. Since then,

20 there has been ever-increasing interest in studying how colouration is tied to different

21 aspects of frog behaviour, ecology and evolution. Here I review the literature on three

22 different contexts in which frog colouration has been recently studied: predator-prey

23 interactions, intraspecific communication, and habitat use; and I highlight those aspects

24 that make frogs an excellent, yet understudied, group to examine the role of colour in the 
1 evolution of anti-predation strategies and animal communication systems. Further, I

2 argue that in addition to natural-history observations, more experiments are needed in

3 order to elucidate the functions of anuran colouration and the selective pressures

4 involved in its diversity. To conclude, I encourage researchers to strengthen current

5 experimental approaches, and suggest future directions that may broaden our current

6 understanding of the adaptive value of anuran colour pattern diversity.

7

8 Key words: colouration, predator-prey interactions, visual communication, sexual

9 selection, conflict resolution, space use.

10

11 CONTENTS

12 I. Introduction

13 II. Predator-prey interactions

14 (1) Camouflage

15 (2) Aposematism and mimicry

(a) The puzzle of polymorphic warning signals

(b) Honesty in warning signals

18 (3) Conspicuous colouration revealed through movement or behaviour

19 III. Intraspecific communication

(1) Mate preferences and assortative mating

(a) Colours can attract both mates and predators

(b) Sexual dichromatism

(2) Intrasexual competition and conflict resolution

24 IV. Habitat selection and space use

25 V. Future directions 
1 VI. Conclusions

2 VII. Acknowledgements

3 VIII. References

4

\section{I. INTRODUCTION}

6 "An extensive survey of the organic world thus leads us to the conclusion that colour is

7 by no means so unimportant or inconstant a character as at first sight it appears to be;

8 and the more we examine it the more convinced we shall become that it must serve some

9 purpose in nature, and that besides charming us by its diversity and beauty it must be

10 well worthy of our attentive study, and have many secrets to unfold to us." - A. R.

11 Wallace $(1877$, p. 643)

12 Signals are supposed to evolve so that the signal-to-noise ratio (the contrast

13 between the signal and the background noise) is maximised (Bradbury \& Vehrencamp,

14 2011; Endler, 1992, 1993a), while signal degradation is minimised (Endler, 1992).

15 Selection also tends to favour signals with a high efficacy not only in terms of their

16 transmission and detection, but also in their ability to elicit a response in the receiver

17 that increases the sender's fitness (Guilford \& Dawkins, 1991) while maintaining the

18 receiver's fitness unaffected. An exception to this is deceptive signals, which deliver

19 incorrect information about the signaller and thus benefit the sender at the expense of the

20 receiver (Mokkonen \& Lindstedt, 2015; Wiley, 1983, 1994).

21 Different modalities of communication entail diverse advantages and constraints

22 on the signals involved (Bradbury \& Vehrencamp, 2011). Acoustic signals can be

23 advantageous over long distances because sound waves can travel for longer through

24 either air or water without degrading compared to, for example, light. This is particularly

25 useful for nocturnal animals given the low or non-existent light levels at night (Bradbury 
1 \& Vehrencamp, 2011). Chemical or olfactory signals are also good in low-light

2 scenarios, but they rely heavily on the characteristics of the medium in which they are

3 transmitted (Bradbury \& Vehrencamp, 2011). Visual signals, on the other hand, work

4 well over short to medium distances provided there is a lack of physical obstacles

5 between the sender and the receiver, suitable contrast with the background, and a

6 minimum of environmental light (Endler, 1992, 1993a); they can have different shapes

7 and sizes, and may convey information either on their own (static signals; e.g. diverse

8 and conspicuous colour patterns in bird plumage; Andersson, 1994) or when

9 accompanied or enhanced by repeated movements or displays (dynamic signals; e.g. the

10 extension of a coloured dewlap in combination with head bobbing in Anolis lizards;

11 Losos \& Chu, 1998).

12 The role of colour patterns as visual signals in animal behaviour and ecology has

13 been studied extensively in a variety of contexts and taxa, but has been neglected in

14 others. For example, for decades anurans have been the focus of studies on acoustic

15 signalling due to the prominence of vocalisations in their communication system. Not

16 only has it been demonstrated that frogs emit calls with different functions (Gerhardt \&

17 Huber, 2002), but they have also been shown to have outstanding sensory abilities that

18 allow them to be both physiologically (Capranica \& Moffat, 1983) and behaviourally

19 (Amézquita et al., 2011) tuned to the characteristics of their own species-specific

20 acoustic signals. By contrast, the link between colouration and the behavioural and

21 evolutionary ecology of anurans had not been properly addressed until approximately

22 two decades ago. Previous studies focused mostly on the inheritance of colour patterns

23 (Blouin, 1989; Davison, 1963; Fogleman, Corn \& Pettus, 1980; Resnick \& Jameson,

24 1963); but see Nevo, 1973, for an early study on the selective pressures involved in the

25 maintenance of colour polymorphism in cricket frogs). Recently, more attention has 
1 been paid to the enormous diversity of colours, colour patterns, and other types of visual

2 signals displayed by frogs (e.g. Hödl \& Amézquita, 2001), and how those signals are

3 tied to different aspects of frog ecology and behaviour. Here I aim to review the

4 diversity of frog colouration in relation to behaviour and ecology. I do so whilst

5 focusing on those cases in which colour patterns are visual signals on their own,

6 describing how these signals are currently thought to function in the context of anti-

7 predation strategies, intraspecific communication and habitat use. Lastly, I suggest

8 future directions within each context that might fill some of the current gaps in frog

9 colouration research; and highlight the need to strengthen and broaden the current

10 experimental approaches in order to widen our understanding of the adaptive value of

11 diversity in frog colouration, and to identify the candidate selective pressures that might

12 be shaping such diversity.

13

\section{II. PREDATOR-PREY INTERACTIONS}

15 Colouration may have an enormous effect on animals' fitness because of its adaptive 16 function as an interspecific signal in the context of predation, among others. While some 17 animals gain protection from predators by blending with their surroundings 18 (camouflage; Edmunds, 1974), many species also have conspicuous colour patterns that 19 warn predators about their unprofitability (Ruxton, Sherratt \& Speed, 2004). The latter 20 strategy is referred to as aposematism (Poulton, 1890).

\section{2 (1) Camouflage}

23 Camouflage involves a series of strategies that prevent prey from being detected or 24 recognised by predators (Edmunds, 1974; Stevens \& Merilaita, 2009). Such strategies 25 include, for instance, crypsis and masquerade. Common types of crypsis are background 
1 matching, whereby an animal resembles its background colouration and thus avoids

2 detection (Endler, 1988), and disruptive colouration, which involves markings that make

3 it difficult for the predator to distinguish the outline or shape of the prey (Cott, 1940;

4 Thayer, 1909). Masquerade, whereby animals resemble an uninteresting object in their

5 surroundings (i.e. a rock, a leaf, a stick, etc.), prevents prey recognition instead

6 (Skelhorn et al., 2010). Both crypsis and masquerade ultimately deprive the predator of

7 key information about the prey and, therefore, constitute a form of deception (Caro,

8 2014; Mokkonen \& Lindstedt, 2015). Camouflage is a widespread anti-predator strategy

9 among anurans, which is reflected in the prevalence of earthy colours such as different

10 shades of green, brown and grey in many species (Wells, 2007). It can be effective on its

11 own, as in young Pristimantis zeuctotylus whose colour patterns resemble those of the

12 mossy substrate (Fig. 1A), or Hyla japonica, which changes its dorsal colour to match

13 that of the background (Choi \& Jang, 2014); but can also be enhanced with particular

14 behaviours. Individuals of Craugastor fitzingeri, for example, become completely

15 immobile after every jump and can also hide their head in the leaf litter; experiments

16 with human observers who knew exactly where to search but still could not easily locate

17 individuals have demonstrated that the detection of these frogs can be extremely difficult

18 for predators (Cooper, Caldwell \& Vitt, 2008).

19 Colour pattern polymorphisms [the simultaneous occurrence of two or more forms

20 within a population with the rarest form occuring at frequencies higher than those

21 expected by mutation pressure (Ford, 1945)] are very common among cryptically

22 coloured species, and frogs are no exception (Hoffman \& Blouin, 2000; Wells, 2007).

23 For example, the frequencies of colour patterns (grey, green, and red) in two species of

24 Acris (A. gryllus and A. crepitans) are correlated locally with variations in substrate

25 colour (Nevo, 1973). Remarkably, these species show seasonal variation in the 
1 frequencies of each colour pattern, suggesting that a morph that is, for example,

2 favoured in spring when everything is green, will not be favoured in the autumn, when

3 the background vegetation will be more red. Likewise, in Dendropsopus (formerly Hyla)

4 labialis, a frog species with an extensive latitudinal and altitudinal distribution, there are

5 at least five distinct morphs whose frequency seems to be correlated with the

6 predominant background at each location. For instance, individuals with spotted colour

7 patterns are more common in populations at high elevations, where the background

8 vegetation is dominated by mosses (Amézquita, 1999). This suggests that colour

9 polymorphism in this species may have evolved as a form of crypsis (Amézquita, 1999).

10 Interestingly, colour patterns also seem to be related to body size, so that green-

11 dominated morphs are smaller than brown ones (Amézquita, 1999), pointing at a

12 potential link between colouration and life-history traits that has been surprisingly

13 understudied in anurans. A long-term study on Eleutherodactylus coqui in Puerto Rico

14 revealed the existence of 21 distinct pattern morphs whose frequencies also differ among

15 populations and are correlated with the background colouration (Woolbright \& Stewart,

16 2008). Individuals with longitudinal dorsal stripes were most common in grassland

17 areas, whereas individuals with spots and bars were more common in the forest

18 (Woolbright \& Stewart, 2008). Likewise, females of Rhinoderma darwinii, which are

19 mostly brown, are found on brown substrates, whereas males, which can be either green

20 or brown, are distributed across brown, green and brown-green backgrounds (Bourke,

21 Busse \& Bakker, 2011).

22 In general, the association between body and background colouration suggests that

23 frogs try to reduce predation risk through crypsis. Cryptic polymorphic species may

24 have an advantage over monomorphic ones if they are exposed to predators that prey

25 disproportionately on the most common phenotypes (apostatic selection), because the 
1 fitness of each morph will be inversely related to its frequency in the population (Allen

2 \& Greenwood, 1988; Bond, 2007; Bond \& Kamil, 1998; Endler, 1991a). Thus, by being

3 polymorphic the per capita predation risk of a given species might be reduced, as the

4 abundance of any of its morphs would be low compared to a monomorphic species

5 (Endler, 1991a). Despite the prevalence of colour pattern polymorphisms among

6 cryptically coloured anurans, the mechanisms that allow for their maintenance remain

7 rather obscure. According to Hoffman \& Blouin (2000), there is evidence that variation

8 in colour patterns can be inherited and strong indications that predation could indeed be

9 the selective pressure behind such diversity, but with a few exceptions (Morey, 1990;

10 Tordoff, 1980; Wente \& Phillips, 2005) most evidence to date remains merely

11 correlational.

12 Although there are many frog examples illustrating the benefits of background

13 matching, evidence describing the function of disruptive colouration or masquerade is

14 very limited and mostly anecdotal. Indeed, despite the fact that it has been suggested to

15 be common among anurans (Wells, 2007), disruptive colouration has not been purposely

16 examined experimentally (Rudh \& Qvarnström, 2013). Examples of what might be

17 disruptive colouration are markings such as light dorsal stripes, and blotches or spots

18 that hinder definition of the body shape or break up the limbs (Wells, 2007), as well as

19 lateral lines that cross the eyes while confounding their shape (Amat, Wollenberg \&

20 Vences, 2013; Toledo \& Haddad, 2009). The best-known illustration of masquerade, on

21 the other hand, is probably found in species living in forests, which can presumably trick

22 predators by looking like dead leaves (Duellman \& Trueb, 1994), such as some species

23 of the genus Rhinella (Fig. 1B-D).

24 Attempts to demonstrate the adaptive value of any of these forms of camouflage,

25 or to test specifically for the role of predators as the selective pressure behind this 
1 diversity in protective colour patterns (i.e. through apostatic selection), could benefit

2 from the use of well-established protocols employed in other systems. For example,

3 experiments with both human and avian predators foraging on either artificial prey

4 items, or virtual prey on computer screens have demonstrated that certain colour patterns

5 increase prey survival, via background matching or disruptive colouration, implicating

6 the role of visual predators as a selection agent on the evolution of diverse protective

7 colouration (Allen \& Clarke, 1968; Allen \& Greenwood, 1988; Bond \& Kamil, 2006;

8 Fraser et al., 2007; Karpestam, Merilaita \& Forsman, 2013, 2014). An alternative

9 approach to tackle similar kinds of questions, which has been widely used for research

10 on aposematism (see Section II.2), is to deploy artificial prey in the field and document

11 and compare attack rates on different morphs by natural visual predators (Cuthill et al.,

12 2005; Farallo \& Forstner, 2012; Valkonen et al., 2011). Studies involving actual frogs

13 would also be highly informative, as they can account for decisions made by the

14 individual frogs themselves. For instance, in an elegant experiment investigating

15 whether individuals of two different morphs of Hyla regilla expressed colour pattern-

16 mediated microhabitat selection, chemical cues of a snake predator were used to

17 evaluate how predator presence affected the frogs' choice (Wente \& Phillips, 2005). The

18 authors found that, in the presence of predator cues, both green and brown frogs

19 preferred a substrate that matched their own colour. In the absence of predator cues,

20 however, only green frogs exhibited a significant preference for a matching background,

21 which suggests a possible genetically linked association between phenotype (i.e. dorsal

22 colouration) and behaviour (i.e. preference for a matching background) (Wente \&

23 Phillips, 2005).

24 Finally, the combination of these kinds of experiments with methods that allow for 25 detailed analyses of colour patterns while accounting for predator perception (Endler, 
1 1978, 1984, 1990, 2012; Endler \& Mielke, 2005; Kemp et al., 2015; Osorio \&

2 Srinivasan, 1991; Renoult, Kelber \& Schaeffer, 2015; Voroyeb \& Osorio, 1998;

3 Voroyeb et al., 1998) opens a broad range of possibilities to study the evolution of

4 camouflage strategies in anurans. For instance, a field experiment where dummies with

5 different colour patterns are deployed on different backgrounds to evaluate how attack

6 rates differ among groups could be complemented with a survey of the actual frogs in

7 their natural habitat, recording information on the exact spot where each individual is

8 found. If not only this information is collected, but also standardised photographs are

9 taken of both the individual frog and its microhabitat, similarities between the frog

10 colour patterns and its background could be measured, and the accuracy of camouflage

11 quantified.

13 (2) Aposematism and mimicry

14 Aposematism is an anti-predator strategy through which prey warn predators about their

15 unprofitability (presence of toxins or physical defences such as spines or irritant hairs)

16 by means of specific colour patterns that act as warning signals (Cott, 1940; Poulton,

17 1890; Rojas, Valkonen \& Nokelainen, 2015b; Ruxton et al., 2004). This strategy works

18 in such a way that predators learn the association between the warning signals and the

19 unprofitability of the prey, and subsequently avoid them (Endler, 1991a; Endler \&

20 Mappes, 2004; Ruxton et al., 2004).

21 Several species of frogs exhibit conspicuous colouration and have a wide array of

22 skin toxins (Wells, 2007), such as various species of Mantella (Fig. 2A,B) and the

23 'Tomato frogs' (genus Dyscophus, Microhylidae; Fig. 2C) from Madagascar (Garraffo

24 et al., 1993a); the Corroboree frogs (Pseudophryne corroboree; Fig. 2D) and other

25 myobatrachids from Australia (Daly et al., 1990); Brachycephalus ephippium from 
1 Brazil (Fig. 2E) (Sebben et al., 1986); and numerous species of Bufonids in the genera

2 Melanophryniscus (Fig. 2F) (Garraffo et al., 1993b; Grant et al., 2012) and Atelopus

3 (Fig. 3A,B; Kim, Kim \& Yotsu-Yamashita, 2003) from South and Central America.

4 However, probably the best-known example of aposematic frogs are the dart poison

5 frogs (Dendrobatidae; Fig. 4) (Stynoski, Shelton \& Stynoski, 2014). The varied toxins

6 found in this Neotropical frog family (Daly et al., 2002, 1994; Daly \& Myers, 1967;

7 Myers \& Daly, 1976, 1983) are sequestered from their specialised diet (Saporito et al.,

$82007 a, 2004)$, which consists mainly of ants, termites, mites and other arthropods found

9 in the leaf litter (Darst et al., 2005; Toft, 1995). Toxins vary noticeably within the family

10 in composition, amount, and power, but most are lipophilic alkaloids (Saporito et al.,

11 2012). One dendrobatid species, Phyllobates terribilis (Fig. 4D), has the most potent

12 non-proteolytic (alkaloid) toxin among vertebrates, batrachotoxin (Myers, Daly \&

13 Malkin, 1978). Each of these golden yellow or metallic orange frogs can have up to 1.2

$14 \mathrm{mg}$ of toxin which, if it comes into contact with an open wound, could potentially be

15 lethal to humans in a dose as low as $200 \mu \mathrm{g}$ (Myers et al., 1978).

16 During the last 15 years, various studies have demonstrated an evolutionary link

17 between colouration and toxicity in dendrobatid frogs (Darst et al., 2005; Santos,

18 Coloma \& Cannatella, 2003; Summers, 2003; Summers \& Clough, 2001), suggesting

19 that bright colouration has evolved independently at least three times. Diet

20 specialisation, which is in turn linked with higher levels of toxicity (Darst et al., 2005),

21 might have itself evolved independently at least two, but possibly three times (Santos et

22 al., 2003; Vences et al., 2003). The combination of bright colours and high toxicity in

23 these frogs has traditionally been put forward as an example of aposematism (Myers \&

24 Daly, 1983; Pough et al., 2001), even though the first experimental attempts to show

25 predator aversion of colourful dendrobatids only took place a few years ago (Saporito et 
$1 a l ., 2007 b$ ). While it has been suggested that some crabs, snakes, beetle larvae and

2 spiders feed on dendrobatid tadpoles (Gray \& Christy, 2000; Stynoski et al., 2014), and

3 some seemingly toxin-resistant snakes might feed on juveniles (Myers et al., 1978), the

4 major predators of adult poison frogs are still not known with certainty, presumably due

5 to the frogs' success at deterring predators. As indicated by anecdotal observations and

6 experiments in the field, ants, Paraponera clavata (Fritz, Rand \& Depamphilis, 1981),

7 and spiders, Cupiennius coccineus (Szelistowski, 1985) and Sericopelma rubronitens

8 (Gray, Kaiser \& Green, 2010), reject them as prey; but there are also some accounts of

9 fish (Santos \& Cannatella, 2011), snake (Fig. 5A) (Lenger, Berkey \& Dugas, 2014;

10 Ringler, Ursprung \& Hödl, 2010), and spider (T. Larsen, personal communication; Fig.

$115 B$ ) predators. Experiments with frog clay models (see below), suggest that poison frogs

12 could be subject to attack by birds and crabs. These results are in agreement with at least

13 one observation of a crab feeding on an individual of Oophaga histrionica in the Chocó

14 region of Colombia (A. Vélez \& S. Körting, personal communication; Fig. 5C), and two

15 observations of adult rufous motmots (Baryphthengus martii) consuming one individual

16 of D. auratus with no apparent negative effects (Master, 1999) or feeding individuals of

17 O. pumilio to their offspring (Alvarado, Alvarez \& Saporito, 2013) (Fig. 5D). Additional

18 evidence obtained in studies incorporating taxon-specific vision modelling (Crothers \&

19 Cummings, 2013; Dreher, Cummings \& Pröhl, 2015; Maan \& Cummings, 2012)

20 indicate that the colour patterns of poison frogs are indeed likely to be designed to signal

21 primarily to birds and crabs. However, it is important to note that both these vision

22 models and the experiments with clay models are unable to assess the importance of

23 predators such as snakes, which do not rely predominantly on visual cues for prey

24 detection, but use mostly olfactory, thermal or movement cues instead (Saviola,

25 McKenzie \& Chiszar, 2012). 
1 Further support for the role of poison frog colour patterns as an anti-predator

2 strategy has been obtained in recent studies. Various field experiments have shown that

3 colourful models representing local frogs are usually less frequently attacked than dull

4 models, models representing novel morphs, or familiar models placed on novel

5 backgrounds, at least for colours resembling the morphs of Oophaga pumilio in Costa

6 Rica (Hegna et al., 2011; Saporito et al., 2007b; Stuart, Dappen \& Losin, 2012) and

7 Dendrobates tinctorius in French Guiana (Noonan \& Comeault, 2009; Rojas, Rautiala \&

8 Mappes, 2014b). Interestingly, an experiment carried out in Isla Colón (Panamá) showed

9 that the local, green morph of $O$. pumilio was attacked at significantly higher frequency

10 than the foreign, red morph from the mainland (Hegna, Saporito \& Donnelly, 2013).

11 According to the authors, this result suggests that red might be a more efficient predator-

12 deterrent warning signal regardless of what the local signal is. Finally, movement has

13 been shown to affect attack rates on clay models of different colours (Paluh, Hantak \&

14 Saporito, 2014). In a study comparing attack rates on stationary brown and red clay

15 models to those on moving models of the same colours, Paluh et al. (2014) demonstrated

16 that not only was bird predation significantly higher on moving brown frog models, but

17 also significantly lower on moving red frog models. These findings provide evidence of

18 the significance of prey movement for visual predators, and highlight the importance of

19 incorporating elements that offer more representative measures of predation in the wild

20 into clay model experiments.

21 In addition to aposematism per se, studies demonstrate that both Batesian (a

22 palatable species mimicking the colouration of a defended one; Bates, 1862) and

23 Müllerian (two defended species sharing similar colour patterns; Müller, 1878) mimicry

24 exist among frog species. In Ecuador, the aposematic frogs Ameerega (Epipedobates)

25 bilinguis (Fig. 4B) and A. parvula occur parapatrically and serve as models to their non- 
1 defended mimic, Allobates zaparo, which adopts the corresponding colouration of its

2 model at each locality (Darst \& Cummings, 2006; Darst, Cummings \& Cannatella,

3 2006). Likewise, Allobates femoralis (Fig. 6A, right), an Amazonian species with a wide

4 geographic distribution and great interpopulational variation in the colouration of both

5 their inguinal and axillary patches, has been thought to be a Batesian mimic of

6 Ameerega hahneli (Fig. 6A, left) (Amézquita et al., 2009). Ranitomeya imitator from

7 Peru, on the other hand, is by far the best-known example of a Müllerian mimetic

8 radiation in amphibians (Symula, Schulte \& Summers, 2001; Twomey, Vestergaard \&

9 Summers, 2014; Twomey et al., 2013). This species (Fig. 6H-K) has diverged in both

10 colour pattern and brightness among populations to resemble the colour patterns of its

11 putative defended models: $R$. variabilis (Fig. 6D, highland morph; Fig. 6G, lowland

12 morph), R. summersi (Fig. 6E), and R. fantastica (Fig. 6F) (Yeager et al., 2012; but see

13 Chouteau et al., 2011). Recent experiments with chickens have demonstrated that

14 models and mimics in this complex might indeed share the costs of predator learning

15 (Stuckert, Venegas \& Summers, 2014b). Furthermore, a comparison between the

16 alkaloid profiles of mimics and models has confirmed that all co-mimics possess

17 chemical defences (Stuckert et al., 2014a). Reciprocal learned avoidance by predators

18 and possession of secondary defences by all the species in the mimetic complex are two

19 fundamental assumptions of Müllerian mimicry (Müller, 1878). Among frogs, however,

20 these assumptions have been tested and confirmed only for the $R$. imitator complex thus

21 far. Another case of Müllerian mimicry was recently proposed, without further

22 experimental support, where the leptodactylid Leptodactylus lineatus (Fig. 6C)

23 previously thought not to be chemically defended, resembles the colouration of the

24 dendrobatid Ameerega picta (Fig. 6B) (Prates et al., 2012). Also, phylogenetic analyses

25 used to study the evolution of colour patterns in Malagassy poison frogs (genus 
1 Mantella) suggest that the convergence in colouration between M. madagascariensis

2 and M. baroni (Fig. 2A), which occur sympatrically, may represent another case of

3 Müllerian mimicry (Schaefer, Vences \& Veith, 2002). This hypothesis, however, has not

4 been tested either. Therefore, given the great variability in toxicity and colour patterns

5 within anurans, and the co-occurrence of toxic with nontoxic species in wide

6 geographical ranges, it seems likely that even more examples of both types of mimicry

7 are waiting to be uncovered.

8

9 (a) The puzzle of polymorphic warning signals

10 Warning signal variability may reduce the ability of predators to learn and retain

11 the association between colour patterns and distastefulness (Exnerová et al., 2006;

12 Greenwood, Wood \& Batchelor, 1981; Mallet \& Joron, 1999). As a result of stabilising

13 selection, it is expected that aposematic prey will have little to no variation in their

14 warning signals (Darst \& Cummings, 2006; Endler, 1988; Endler \& Mappes, 2004;

15 Joron \& Mallet, 1998). Hence, polymorphisms should be selected against in aposematic

16 species (Endler \& Mappes, 2004). However, there are several cases of aposematic

17 species exhibiting colour polymorphisms in nature, for example ladybirds (O'Donald \&

18 Majerus, 1984; Ueno, Sato \& Tsuchida, 1998), beetles (Borer et al., 2010) and moths

19 (Hegna, Galarza \& Mappes, 2015). In anurans, despite many aposematic species

20 showing geographic variation in colouration (Amézquita et al., 2013; Brusa et al., 2013;

21 Chouteau et al., 2011; Hoogmoed \& Avila-Pires, 2012; Lötters et al., 1997; Myers \&

22 Daly, 1983; Noonan \& Gaucher, 2006; Wollenberg et al., 2008), within-population

23 variability in warning signals has been reported only for Oophaga pumilio (Fig. 7A-D)

24 (Maan \& Cummings, 2012), O. histrionica (Amézquita et al., 2013), Dendrobates

25 tinctorius (Rojas \& Endler, 2013) (Fig. 7E-H) and Melanophryniscus rubriventris (Fig. 
1 3C) (Bonansea \& Vaira, 2012). Nevertheless, given that levels of variation have not

2 been investigated in many species, it is highly likely that more examples are yet to be 3 discovered.

4 Although there are several instances of polymorphic aposematic populations, the

5 mechanisms allowing warning signal polymorphisms to persist are not yet fully

6 understood. Recent approaches suggest a number of possible explanations: (1) an

7 interaction between natural and sexual selection (Crothers \& Cummings, 2013;

8 Cummings \& Crothers, 2013; Nokelainen et al., 2012); for example, in the aposematic

9 wood tiger moth (Parasemia plantaginis), where males can be either yellow or white,

10 yellow individuals have been found to be better protected from predators, whereas under

11 certain circumstances whites have a higher mating success (Gordon et al., 2015;

12 Nokelainen et al., 2012). In O. pumilio from Solarte Island (in the Bocas del Toro

13 archipelago), the stabilising selection exerted by predators to keep colour patterns

14 uniform is most likely counteracted by directional sexual selection favouring brighter

15 males, which are preferred by females (Maan \& Cummings, 2009). (2) Spatio-temporal

16 variation in selection (Endler \& Rojas, 2009; Galarza et al., 2014; Nokelainen et al.,

17 2014), for instance in the composition of local predator communities, which may

18 generate a geographic mosaic of selection throughout the distribution range of a species.

19 (3) A link between colour patterns and a fitness-related trait (or group of traits), either

20 behavioural or physiological. Examples of this are differential activity patterns and

21 investment in immune defences according to colour, as in wood tiger moths, or the

22 association between movement type and colour patterns in the dyeing poison frog

23 (Dendrobates tinctorius) (Nokelainen, Lindstedt \& Mappes, 2013; Rojas,

24 Devillechabrolle \& Endler, 2014a; Rojas, Gordon \& Mappes, 2015a). (4) Relaxed

25 selection towards warning signals or predator generalisation, which involves predator 
1 avoidance of one signal and the expansion of this aversion towards other signals similar

2 enough to the one learnt (Amézquita et al., 2013; Darst et al., 2006; Richards-Zawacki,

3 Yeager \& Bart, 2013). (5) Non-adaptive forces such as hybridisation among geographic

4 variants or drift (Gray \& McKinnon, 2007; Medina et al., 2013; Thompson, 1984).

5 Whatever the mechanism, for polymorphisms to be maintained there should be no

6 differences in fitness among the morphs.

7

8 (b) Honesty in warning signals

The 'handicap principle' (Zahavi, 1975) suggests that selection should favour signals that provide reliable information about an individual's quality. These signals must represent costs for the signaller, so that they are unaffordable for individuals whose quality is lower. Although suggested originally for sexual signals, honest signals have the potential to evolve in predator-prey relationships as well (Guilford \& Dawkins, 1993).

For aposematic individuals, it is likely that warning signals are reliable indicators of prey's unprofitability (e.g. toxicity), as only well-defended prey can afford the costs of being easily detectable by predators (Sherratt, 2002). However, detectability is not necessarily the only cost aposematic species may incur. Theoretical studies have shown that simultaneous investment in pigments and chemical defences may trade off within the same individual (Blount et al., 2009). Thus, warning signals are likely to be honest signals of the quality (or quantity) of chemical defences, as only well-defended individuals could profitably tolerate the costs of strong warning signals.

A positive correlation between warning signals and toxicity has been found across species of dart poison frogs in a study where phylogenetic constraints were taken into account, and where both colouration and toxicity were considered 'either/or' traits 
1 (Summers \& Clough, 2001). However, quantitative approaches to whether poison frogs'

2 warning signals are honest or not have yielded mixed evidence. For instance, among

3 different populations of Oophaga pumilio colouration has been suggested to be an

4 honest indicator of toxicity, such that the brightest populations are also the most toxic

5 (Maan \& Cummings, 2012). However, a negative correlation between these two traits

6 has also been found, both between and within species. The conspicuous species

7 Ameerega (Epipedobates) bilinguis has a lower toxicity level than its less-conspicuous

8 counterpart, Ameerega (Epipedobates) parvulus (Darst et al., 2006). Notably,

9 experiments with chicks revealed that both increased conspicuousness and increased

10 toxicity are equally effective when it comes to predator deterrence (Darst et al., 2006).

11 Likewise, in different populations of Oophaga granulifera conspicuous colouration and

12 toxicity are inversely related, such that the most conspicuous populations show the

13 lowest levels of toxicity. In fact, these populations, where individuals are bright red, lack

14 four of the alkaloids present in populations with the less conspicuous yellow or green

15 colouration (Wang, 2011). According to Blount et al. (2009), this scenario is plausible

16 when resource availability is high, as suggested for the seven-spot ladybird, Coccinella

17 septempunctata (Blount et al., 2012). However, a recent theoretical approach found that,

18 at equilibrium, a negative correlation between conspicuousness and defence strength

19 does not hold (Holen \& Svennungsen, 2012). This is because, if a trade-off between the

20 resources invested in warning signals and chemical defences is assumed, the benefit of

21 more conspicuous signals is a low risk of prey being attacked after detection, whereas

22 the cost is a reduced defence level, which will bring decreased probabilities of survival

23 upon attack (Holen \& Svennungsen, 2012). Toxins such as those found in dendrobatid,

24 mantellid or bufonid frogs are believed to be mainly sequestered from their diet (Clark et

25 al., 2005; Daly et al., 1997; Hantak et al., 2013), which consists primarily of leaf-litter 
1 arthropods. This means that, as suggested by previous studies (Maan \& Cummings,

2 2012; Wang, 2011), variation in toxicity levels among populations of the same species

3 might be due to variation in prey availability. However, this does not necessarily explain

4 why some species (or individuals within the same population) are more toxic, or more

5 conspicuous, than others.

Finding correlations, either positive or negative, between warning signals and the

7 quality or quantity of chemical defences in the species mentioned above has been very

8 informative on the dynamics of predator-prey relationships in anurans. However,

9 empirical studies tend to miss one (or more) of the key elements about honesty, such as

10 evidence that predators really pay attention to variation in toxicity and/or see (and care

11 about) the difference among signals. Often only a correlation between toxicity and

12 colouration is found, and the rest is assumed. Therefore, as Summers et al. (2015) state

13 in a recent review, one key question is how to differentiate between quantitative honesty

14 and other ways in which conspicuousness and toxicity may be correlated without

15 involving honest signalling.

16 The next steps thus should also include observations and experiments leading to a

17 better understanding of the costs associated both with toxin sequestration and storage,

18 and with the production of warning signals (i.e. pigments). For example, in species with

19 variable colour patterns, it could be tested whether in cohorts of individuals raised from

20 larvae in the same conditions, juvenile colour patterns are correlated with life-history

21 traits such as size and time to metamorphosis. Additionally, juveniles could be raised in

22 semi-natural enclosures differing in diet restrictions to see whether resource availability

23 affects colouration, or toxicity, or both. A primer on this is a recent study on

24 Dendrobates auratus, where the effects of rearing tadpoles on either a high-food or low-

25 food diet were tested on body size and luminance at metamorphosis (Flores et al., 2013). 
1 The authors found that in metamorphs raised on a high-food diet body size and

2 luminance were negatively correlated, whereas this correlation was positive in froglets

3 reared on a low-food diet. According to Flores et al. (2013), these findings suggest

4 either a trade-off in resource allocation, or developmental plasticity aimed at minimising

5 predation risk at the most vulnerable (early) stages. Life-history trade-offs in relation to

6 frog colouration may therefore be more common than usually thought, especially if the

7 resource-allocation hypothesis holds.

8

9

\section{(3) Conspicuous colouration revealed through movement or behaviour}

Besides the very well-studied active visual displays that some frog species perform with their fore and hind limbs (i.e. arm waving, foot flagging, etc.), some of which expose coloured patches (reviewed in Hödl \& Amézquita, 2001), several anuran species reveal coloured parts of their body through movement or specific positions (Hödl \& Amézquita, 2001). Some species that use camouflage as their primary defence against predators have a secondary 'hidden' conspicuous colouration which is revealed under threat (i.e. deimatic displays; Edmunds, 1974; Umbers, Lehtonen \& Mappes, 2015). Species in the genera Phyllomedusa and Agalychnis, for example, have this kind of colouration on their flanks (Fig. 8A). Their markings display combinations of yellow, orange, or purple with black stripes, and might serve as a warning signal to their irritating skin secretions (Wells, 2007, and references therein) and strong smell (B. Rojas, personal observations) when handled. The anti-predator function of these colour patterns warrants experimental testing. Species of the genera Physalaemus, Pleurodema and Edalorhina exhibit what resemble eyespots in the lower part of their dorsum (Fig. 8B). These markings are better seen when the frogs hide their head in the substrate, leaving visible only the posterior part of the body (Lenzi-Mattos et al., 2005; Martins, 
1 1989). Fire toads of the genus Bombina expose their conspicuous ventral colouration by

2 raising the legs and arching their body ('unken reflex') when threatened (Bajger, 1980).

3 This behaviour is also common among South American frogs of the genus

4 Melanophryniscus (Fig. 8C-E) (Caorsi et al., 2014; Grant et al., 2012; Santos \& Grant,

5 2011). Finally, the conspicuous and very distinctive ventral colouration exhibited by

6 some species of Atelopus (Fig. 3B) has also the potential to deter predators, especially

7 given the highly toxic tetrodotoxins present in the genus (Fuhrman, Fuhrman \& Mosher,

8 1969; Kim et al., 2003), but this hypothesis also requires in-depth examination.

9

\section{INTRASPECIFIC COMMUNICATION}

\section{1 (1) Mate preferences and assortative mating}

12 Bright colours can be important signals in mate choice (Andersson, 1994), particularly, 13 but not exclusively, for diurnal species that use a wide range of visual signals during 14 courtship (e.g. poison frogs: Hödl \& Amézquita, 2001; Zimmermann \& Zimmermann, 15 1988). For example, females of different taxa prefer to mate with more colourful or 16 brighter individuals (Bajer et al., 2010; Gomez et al., 2009; Maan et al., 2004). In some 17 cases, not only the colour but also a variety of different criteria such as the number, size 18 or shape of patches or spots are important in mate choice (Petrie, Halliday \& Sanders, 19 1991; Pincemy, Dobson \& Jouventin, 2009). Although in many cases the explanations 20 for mate preferences remain obscure, it has often been found that they are associated 21 with the indirect benefits of 'good genes' (Cutrera, Fanjul \& Zenuto, 2012; Hamilton \& 22 Zuk, 1982; Milinski \& Bakker, 1990; Stange \& Ronacher, 2012). Female preferences 23 can exert directional selection on male traits that provide reliable information about their 24 quality, because high-quality mates presumably lead to higher quality offspring, via 25 increased fitness [through, for example, parasite resistance (Barber et al., 2001; Demuth, 
1 Naidu \& Mydlarz, 2012; Horak et al., 2001; Milinski \& Bakker, 1990) or protection

2 from predators (Lancaster, Hipsley \& Sinervo, 2009; Sheldon et al., 2003)]. In spite of

3 this, there are hardly any studies either on the influence of colouration on mate choice or

4 on the fitness consequences of such choices in anuran species.

5

6 a mate, given their ability to see some colour cues under low light (Gomez et al., 2010).

7 Using video playbacks of frogs emitting identical calls but differing in the colour and

8 brightness of their vocal sac, Gómez et al. (2009) demonstrated that female Hyla

9 arborea are more attracted to males with a more colourful sac and prominent lateral

10 stripe, which may together boost male conspicuousness. Furthermore, given that

11 carotenoid production is costly, the authors hypothesised that carotenoid-based colours

12 in the vocal sac might convey information about male quality (Gomez et al., 2009).

13 Similarly, female Scaphiopus couchii prefer brighter males; in this species, both colour

14 and patterning of males are reliable indicators of body size, which may in turn be an

15 indicator of male quality (Vasquez \& Pfennig, 2007). Finally, when presented with two

16 models differing in colour pattern but emitting identical calls, female Hyla squirrella

17 seem to be more attracted to males with large lateral stripes (Taylor et al., 2011).

18 Among diurnal frogs, the only species in which visual mate choice has been

19 studied extensively to date is Oophaga pumilio. Females in this species have been

20 shown to prefer males with higher dorsal brightness (Maan \& Cummings, 2009).

21 Although ventral colouration could be expected to be more important than dorsal

22 patterns for intraspecific communication given that most interactions occur while frogs

23 are facing each other (Siddiqi et al., 2004), this and other studies support the idea that

24 male dorsal colouration is the most relevant trait on which females base their

25 preferences (Maan \& Cummings, 2008; Summers et al., 1999). Oophaga pumilio has 
1 also been the focus of several studies because of its extensive interpopulation variation

2 in colour patterns, especially in the Bocas del Toro Archipelago in Panama (Fig. 7A-D).

3 Here, at least 15 different morphs have been identified among different islands (Myers

4 \& Daly, 1983; Siddiqi et al., 2004), but, with the exception of one population at Isla

5 Bastimentos, populations of this species are known to be monomorphic. Understanding

6 the origin of such geographic diversity in colour pattern has proved challenging,

7 although there are strong indications that, besides natural selection, sexual selection may

8 play a role in its maintenance (Crothers \& Cummings, 2013; Cummings \& Crothers,

9 2013; Maan \& Cummings, 2009; Summers et al., 1997).

A possible mechanism by which sexual selection can promote the maintenance of

11 geographic variants is through assortative mating, the non-random pairing of two

12 individuals on the basis of a shared trait (Kondrashov \& Shpak, 1998); be it

13 morphological, ecological, or behavioural. Assortative mating has been broadly

14 documented in a wide variety of organisms, and can be either positive (matings between

15 individuals with the same phenotype) or negative (matings between different

16 phenotypes). Colours seem to play a prominent role in the occurrence of assortative

17 mating in taxa such as fish (Maan \& Seehausen, 2011; Seehausen \& van Alphen, 1998;

18 Terai \& Okada, 2011), birds (Andersson, Ornborg \& Andersson, 1998), butterflies

19 (Melo et al., 2009), and frogs. In a set of choice experiments with O. pumilio in the

20 laboratory, females presented with males from two different populations (i.e. two

21 different colour morphs) were more likely to spend time with the male from their own

22 population (Reynolds \& Fitzpatrick, 2007; Summers et al., 1999). Another study, with

23 four populations, found that female mating preferences are influenced by male colours

24 in such a way that native males were favoured, but that this preference relies heavily on

25 the phenotype of the second male that is presented in the experiment (Maan \& 
1 Cummings, 2008). Recent work inferring patterns of colour-based mating in O. pumilio

2 from wild pedigrees indicates that the assortative mating found in the laboratory does

3 not necessarily translate completely to the field, where choices are actually made

4 (Richards-Zawacki, Wang \& Summers, 2012). It would be interesting to determine

5 whether these preference patterns apply to other dart poison frog species with

6 comparable geographic variation in colour patterns (Hoogmoed \& Avila-Pires, 2012;

7 Lötters et al., 2007; Silverstone, 1975). Likewise, it would be intriguing to determine

8 whether colours play a role in mate choice in completely unrelated taxa such as species

9 of the genus Mantella. This group of Malagassy frogs seems a striking example of

10 evolutionary convergence with dendrobatids not only because of their conspicuous

11 colouration (Schaefer et al., 2002) and skin alkaloids (Garraffo et al., 1993a), but also

12 because of their complex social and reproductive behaviour (Heying, 2001). Other

13 suitable candidates for this kind of investigation are species of the genus

14 Melanophryniscus, such as M. rubriventris (Bonansea \& Vaira, 2012).

15

16 (a) Colours can attract both mates and predators

17 One problem that animals face when they have conspicuous colour patterns is that they

18 may be providing information about their presence and location to both wanted and

19 unwanted receivers. While aposematic species have evolved distastefulness as a way to

20 deter predators, unprotected organisms must find a way to efficiently attract conspecifics

21 without attracting too much attention from predators or sneakers (Endler, 1978, 1980).

22 This problem might be overcome by using 'private communication channels' so that

23 conspicuousness is higher towards conspecifics than it is towards predators (Endler,

$241978,1980,1991 b$; Schaefer, 2010), which would imply that the visual sensitivity of

25 conspecifics is better 'tuned' to the characteristics of their visual signals than is the 
1 predators' sensitivity (Endler, 1991b). Alternatively, there could be spatio-temporal

2 constraints on the use of conspicuous signals, for example in species with explosive

3 breeding (i.e. breeding activity limited to only one or a few days, often following the

4 first rains of the season; Wells, 2007, and references therein).

There are various examples of spatio-temporal niche partitioning in frogs, most of

6 which relate to their acoustic signals in complex assemblages (Amézquita et al., 2011;

7 Check, Bogart \& Lougheed, 2003; Duellman \& Pyles, 1983; Lüddecke et al., 2000).

8 Recent studies, however, have shown that such partitioning could also be related to

9 colouration, and occur at an intraspecific level. The toad Bufo luetkeni breeds at the very

10 beginning of the rainy season in Costa Rica. Males of this species, which are otherwise

11 dully coloured, become lemon yellow when they are ready to breed, and combine this

12 conspicuous signal with distinct calls to create a multimodal display that attracts

13 females. Females, as well as recently mated males, are dull brown, which suggests that

14 this temporal change in colouration may be influenced by sexual selection, and restricted

15 in time presumably due to increased risk of predation when conspicuous (Doucet \&

16 Mennill, 2010). In Rana temporaria, males in breeding aggregations display brighter

17 throats (Fig. 9A), whereas male moor frogs (Rana arvalis) turn blue (Fig. 9B). Such

18 colour changes have been suggested to function as a sex-recognition cue to prevent

19 mismating attempts during the intense scramble competition common among explosive

20 breeders (Sztatecsny et al., 2012, 2010).

\section{(b) Sexual dichromatism}

23 The changes in colouration described above occur in just one sex, and are therefore

24 considered examples of sexual dichromatism. Also, because they occur only

25 temporarily, during breeding, they are considered to be 'dynamic'. This type of colour 
1 change has been studied most thoroughly in the context of frog behaviour or ecology.

2 However, due to its visibility for only a short period of time - ranging from a few hours

3 to a few weeks - its occurrence is thought to be underestimated, i.e. it probably is more

4 common than we are aware of in anuran taxa (Bell \& Zamudio, 2012). There are also

5 cases of ontogenetic colour change, where males differ from females in colouration from

6 early life stages (Bell \& Zamudio, 2012). For example, female African reed frogs of the

7 genus Hyperolius change their colour patterns when attaining maturity, whereas males

8 keep their juvenile colours (Veith et al., 2009).

9 In one of the populations of the Bocas del Toro archipelago, the aposematic frog $O$.

10 pumilio is known to be sexually dimorphic in terms of brightness, a non-chromatic

11 component of colour patterns, with adult males as the brighter sex (Maan \& Cummings,

12 2009). This is most likely due to directional sexual selection (Maan \& Cummings,

13 2009). Male Dendrobates tinctorius from a highly polymorphic population in French

14 Guiana, on the other hand, are overall yellower than females. This has been suggested to

15 be the product of a synergy between sexual selection in the form of parental care, and

16 the potential increased predation risk for males during the prolonged exposure involved

17 in tadpole transport (Rojas \& Endler, 2013). Despite these examples, sexual

18 dichromatism is still surprisingly understudied considering how widespread it seems to

19 be among anurans (Bell \& Zamudio, 2012).

21 (2) Intrasexual competition and conflict resolution

22 Intraspecific aggression has been widely documented and can occur in different contexts

23 (Lorenz, 1966; Riechert, 1998). Individuals can behave aggressively against

24 conspecifics when they threaten the survival of their offspring (Sommer, 1987), when

25 they threaten access to potential mates (Andersson, 1994), or when they are defending a 
1 space that holds resources essential for their survival (i.e. food or shelter) or

2 reproduction. The latter case is normally referred to as territoriality (Kaufmann, 1983;

3 Maher \& Lott, 1995). However, aggression via escalated conflict is costly in terms of

4 energy and confers the risk of being injured (Maynard Smith \& Harper, 2005).

5 Therefore, under specific circumstances, the resolution of conflicts via the exchange of

6 signals is expected to be favoured over physical aggression as an evolutionarily stable

7 strategy (Maynard Smith, 1982; Maynard Smith \& Harper, 2005). In fact, the mitigating

8 effect of signalling during agonistic interactions has empirical support (Logue et al.,

$92010)$.

10 During a conflict, contestants should assess the probability of defeat by comparing

11 their own fighting abilities with those of their opponent (Riechert, 1998). This means

12 that both individuals are at the same time senders and receivers, as they exchange

13 information about status, relative fighting ability, and relative resource value. Such

14 information could be given and obtained on the basis of behavioural traits such as the

15 rate at which displays are repeated (Johnstone, 1997). For example male jacky dragons

16 (Amphibolurus muricatus) respond to video playbacks of conspecifics displaying at

17 varying time intervals with aggressive push-ups (Ord \& Evans, 2003). Alternatively,

18 information can be contained in intrinsic characteristics of an individual such as colours,

19 size, condition, or the size or complexity of weaponry such as horns or antlers (Bradbury

$20 \&$ Vehrencamp, 2011).

21 Colouration is a reliable signal of status and an important determinant of conflict

22 resolution for several species of insects, fish, lizards, and birds (López, Martin \&

23 Cuadrado, 2004; Morimoto, Yamaguchi \& Ueda, 2005; Pryke \& Andersson, 2003a;

24 Stuart-Fox \& Johnston, 2005). Not only the colour, but also the size and shape of visual

25 signals may provide information about fighting abilities during agonistic encounters. 
1 There is much evidence that more colourful males, and sometimes females, tend to

2 acquire and retain higher status within a group of individuals, whereas dull-coloured

3 individuals are often subordinate. For example, redder male firemouth cichlids

4 (Cichlasoma meeki) are more likely to win contests than duller ones (Evans \& Norris,

5 1996); and sand lizards (Lacerta agilis) with more colourful badges are more likely to

6 initiate and win fights (Olsson, 1994); Similar trends have been found in African red-

7 shouldered widowbirds (Euplectes axillaris), where individuals with redder patches are

8 more likely to acquire territories and outcompete rivals (Pryke \& Andersson, 2003b).

9 If colour pattern is an honest signal of an individual's ability to defend its territory,

10 one may also expect brighter or more colourful individuals to win contests more often

11 than the dull ones, and thus be more successful in acquiring and maintaining high-

12 quality territories. As predicted, we find many examples of this throughout different

13 taxa. For instance, territorial Augrabies flat lizard (Platysaurus broadleyi) males have a

14 lower ultraviolet reflectance than floaters (Whiting et al., 2006), and the size of the red

15 spots in the wings of male rubyspot damselflies (Hetaerina americana) promotes

16 successful defence of a territory (Grether, 1996).

17 Nearly all anurans defend small, short-term individual spaces during the breeding

18 season, as they confer a particular advantage for the propagation of mating signals or

19 better access to mates (Wells, 2007, and references therein). Dendrobatid frogs seem to

20 be a remarkable exception to this generalisation, as all of the species studied to date

21 exhibit some degree of long-term territoriality (Pröhl, 2005; but see Born et al., 2010).

22 They defend multi-purpose territories that aid in mate attraction (Wells, 2007) and

23 subsequent breeding. Defended resources within each territory vary from species to

24 species (Pröhl, 2005), but are most often related to their elaborate parental care. 
1 Even though most frogs rely on acoustic signals for communication, resident male

2 dendrobatids generally advertise territory ownership to intruders with a combination of

3 acoustic and visual signals (Hödl \& Amézquita, 2001; Zimmermann \& Zimmermann,

4 1988), and in some cases physical combats can occur until the intruder is chased away,

5 or gains the territory over the resident. For example, according to Wells (1980),

6 territorial male Mannophryne (= Colostethus) trinitatis turn black when calling while

7 non-calling males remain brown. Most interestingly, black males seem to react

8 aggressively only towards other black males, and often engage in wrestling. At the end

9 of the encounters, one of the males changes his colour back to brown, which presumably

10 decreases the probability of being attacked by a black male (Wells, 1980). A recent

11 study in laboratory conditions showed that $O$. pumilio males call and approach brighter

12 males more frequently than duller ones. Furthermore, a male's own brightness also

13 predicts his own behaviour, such that brighter males approach stimulus frogs faster and

14 call more towards other bright individuals (Crothers, Gering \& Cummings, 2011). A

15 field study on males of the same species showed that the most aggressive males from

16 eight sampled populations were the ones with the most conspicuous colouration (Rudh,

17 Breed \& Qvarnstrom, 2013).

18 While these links between colouration and behaviour seem to be reported more

19 frequently, the mechanisms explaining how they appear and persist warrant in-depth

20 examination. Correlational selection, which may favour certain combinations of traits

21 (such as behaviour and phenotype) expressed at the same time in an individual without

22 affecting the expression of each trait on its own (Brodie, 1992; Endler, 1986; Sinervo \&

23 Svensson, 2002), may be one possibility. Pleiotropy and gene linkage have also been

24 advocated as possible explanations for the higher levels of dominance of Gouldian 
1 finches (Erythrura gouldiae) bearing a red head, even when their head colour was

2 manipulated to look like the subordinate morphs (Pryke \& Griffith, 2006).

3 Some species need acoustic and visual signals together (like the inflation-deflation

4 of the vocal sac) in order to trigger agonistic behaviour (de Luna, Hödl \& Amézquita,

5 2010; Narins, Hödl \& Grabul, 2003). Thus, the importance of visual signals and the

6 potential role of colouration and colour patterns in the agonistic interactions of species

7 that emit very soft sounds (Dendrobates leucomelas, D. truncatus and D. auratus;

8 Erdtmann \& Amézquita, 2009), or lack an acoustic advertisement call (Dendrobates

9 tinctorius; Born et al., 2010; B. Rojas, personal observations) demands further

10 investigation.

11 As shown above, both male territorial behaviour and male-male aggression have

12 been well documented in dendrobatoids (Pröhl, 2005). Aggression between females, on

13 the other hand, has been poorly studied. Wells (1980) reported aggression between

14 females of Mannophrynne trinitatis. A resident female challenges an intruder by

15 acquiring an upright posture, and pulsating her bright yellow throat. Female

16 Dendrobates auratus behave aggressively by chasing each other or wrestling in the

17 presence of calling males (Summers, 1989). Apart from these studies, no others have

18 been conducted on the role of colours in the agonistic behaviour of female frogs, and

19 reports of its occurrence remain mostly a matter of side observations in male mating

20 behaviour studies (Summers, 1992; Wells, 1978). Female aggression occurs in at least

21 four colourful species: O. pumilio, D. auratus, D. leucomelas (Meuche, Linsenmair \&

22 Proehl, 2011; Summers, 1989, 1992; Wells, 1978) and D. tinctorius (B. Rojas, personal

23 observations). Given that females do not vocalise at all, their means of acquiring,

24 defending, and maintaining resources are still obscure. Hence, species with territorial 
1 females constitute an excellent target for examining the importance of colour patterns

2 during agonistic interactions.

3

4 IV. HABITAT SELECTION AND SPACE USE

5 The distribution of individuals of a species within a particular habitat might be explained

6 by the location of resources or anti-predator refuges, the suitability of different

7 microhabitats, or the preferences of conspecific individuals (Alcock, 2001). There are at

8 least two ways in which colours or colour patterns can be associated with habitat

9 selection and space use. First, animals might choose a habitat that provides the best

10 blending opportunities in order to minimise detection by predators (Ruxton et al., 2004).

11 This can be achieved, for example, either by background matching (Endler, 1984;

12 Pellissier et al., 2011), or by mixing with groups of species with similar colouration

13 (Munday, Eyre \& Jones, 2003). Second, animals can select microhabitats that increase

14 their own conspicuousness or the conspicuousness of their sexual displays (Endler,

15 1993b; Heindl \& Winkler, 2003; Théry, 2001; Théry \& Endler, 2001). Section II.1

16 discussed how some species with cryptic colouration may select the habitat that best

17 matches their colours in order to avoid being detected by predators. By contrast, in this

18 section I will address implications other than background matching of colour-mediated

19 space use and habitat selection.

20 As discussed above, aposematic species rely on their conspicuousness to teach

21 predators about their unprofitability which should lead to monomorphism of the warning

22 signal. However, as explained previously there are many polymorphic (and polytypic)

23 aposematic species. It is possible that these species benefit from colour pattern-mediated

24 habitat selection as a mechanism to maintain colour pattern variability. In such cases,

25 each morph could choose a habitat that maximises its conspicuousness. Alternatively, if 
1 conspicuousness differed among morphs, less-protected individuals could benefit from

2 choosing microhabitats that provide extra protection from predators, for example hiding

3 places. The former seems to be the case for males of $O$. pumilio, which seem to select

4 vocalisation perches that maximise their conspicuousness (Pröhl \& Ostrowski, 2011).

5 Likewise, males from more conspicuously coloured populations of $O$. granulifera (Fig.

$64 \mathrm{G}$ ) tend to call from more exposed perches than populations with duller males (Willink

7 et al., 2013).

8 Aposematic colour patterns may be associated with aspects of space use other than

9 habitat selection. For aposematism to work, prey density must be high (Mappes, Marples

10 \& Endler, 2005; Ruxton et al., 2004; Speed, 2000), or at least above a certain threshold

11 (Endler \& Rojas, 2009), so that the frequency of encounters between the predator and

12 the defended prey enhances predator learning. Therefore, aposematic organisms are

13 assumed to benefit from spatial aggregations (Alatalo \& Mappes, 1996; Lindström et al.,

14 2001; Mappes \& Alatalo, 1997; Riipi et al., 2001), and at least in some taxa it has been

15 demonstrated that gregariousness appeared after warning colouration (Beltrán et al.,

16 2007; Sillén-Tullberg, 1988). This does not necessarily occur in all aposematic species.

17 While colourful dendrobatids are also highly toxic, their strong territorial behaviour

18 makes them unlikely to be aggregated. However, one might predict that the territories of

19 conspicuous species are more aggregated than those of dull-coloured species.

20 Another way to approach the same conceptual problem would be to conduct

21 studies comparing populations of colourful species that differ in abundance. There is

22 good theoretical and increasing experimental support in favour of the idea that spatial

23 variation in selective pressures (i.e. predation) might be a relevant factor shaping the

24 evolution of aposematic signals (Chouteau \& Angers, 2011; Nokelainen et al., 2014;

25 Valkonen et al., 2012), and that the emergence of novel signals can be a frequency- 
1 dependent process (e.g. Endler \& Mappes, 2004; Endler \& Rojas, 2009). To date,

2 however, there is only one empirical study examining how the spatial variation in the

3 frequency of different warning signals may enable the emergence of novel signal types

4 (Comeault \& Noonan, 2011). Using clay models Comeault \& Noonan (2011) compared

5 the attack rate on different morphs of Dendrobates tinctorius in two populations

6 differing in the abundance of the local morph. This study provided evidence that

7 selective pressures affecting the survival rate of a 'protected' morph vary in accordance

8 with its relative abundance in the population. In other words, an aposematic signal that is

9 successful at high densities might not be so when the densities are low.

\section{V. FUTURE DIRECTIONS}

12 Even though the diversity of colours seen in anurans has been documented for decades,

13 only relatively recent studies have directly assessed its function and adaptive

14 significance (reviewed in Rudh \& Qvarnström, 2013). Specifically, greater emphasis has

15 been placed on examining the role that colours and other visual signals play in frog

16 behaviour and ecology, especially in relation to protection from predators and mating.

17 Likewise, current research has increasingly explored the synergy between different

18 sensory modalities during mate attraction and male-male competition. Altogether, this

19 indicates that frogs are excellent subjects for research on the evolution of colour-related

20 anti-predation strategies and intraspecific communication systems. Future research

21 should focus on a variety of key issues listed below.

22 First, experimental approaches could be used to test the efficacy of eyespots and flash

23 colours as signals addressed to potential predators. Among diurnal frogs, predation

24 seems to be the selective pressure that stimulates the most interest among researchers

25 studying colour pattern diversity, but most studies have been carried out in one taxon 
1 only (Neotropical dart poison frogs) even though there is a great array of anuran taxa

2 that possess diverse colour patterns (i.e. Mantellidae, Myobatrachidae, Bufonidae,

3 Brachycephalidae, etc.). Furthermore, many recent studies have used clay models;

4 although these studies represent a significant step forward in the study of warning

5 signals, they are biased towards an overestimation of deaths, i.e. ignoring the fact that an

6 attacked individual may survive. Additionally, research with clay models does not

7 account for predators like snakes, which most likely would not attack the models, or for

8 any behavioural correlates that act in concert with the warning signal. Future research

9 could thus benefit from complementary studies where the survival of individuals bearing

10 different colour patterns is tracked, for example, using capture-mark-recapture methods

11 in semi-natural or wild conditions. Also, given their dissimilar distribution ranges, it

12 would be especially interesting to compare the role of natural and sexual selection in the

13 colour diversification of dendrobatids to that of mantellids, which show remarkable

14 signs of evolutionary convergence in other aspects of their biology.

15 Second, the role of colour patterns is relatively unexplored in mate choice and other

16 aspects of sexual selection such as intrasexual competition, especially in highly

17 territorial species. Studies on how nocturnal species use information conveyed in visual

18 signals and why they may have retained colour vision and coloured traits whose

19 expression may be costly, could refine our understanding of the function and importance

20 of multimodal communication, which has proven increasingly prominent in anurans

21 (Starnberger, Preininger \& Hödl, 2014). Beyond the actual mate preferences, there is not

22 much evidence to date supporting the function of colours as reliable indicators of good

23 genes in frogs. It is unknown, for example, whether females obtain indirect benefits

24 when mating with brighter males or males with certain colour patterns and whether that

25 enhances the survival of their offspring. 
1 Third, there is a surprisingly large gap in studies linking colour patterns and life history,

2 especially in aposematic species. It would be very exciting to know what the costs and

3 constraints are that compromise signal efficacy, and whether colours are honest signals

4 for all receivers (i.e. both conspecifics and heterospecifics), or whether they are instead

5 deceptive.

6 Finally, we must consider other selective pressures besides mate choice and predation in

7 order to investigate how variation in colour patterns can originate and be maintained.

8 Future research should thus focus on exploring more aspects of the behaviour and

9 ecology of the studied species in order to have a better understanding of the function and

10 evolution of the great diversity in colour patterns that exists among anurans today.

\section{VI. CONCLUSIONS}

13 (1) Animals use different modalities of communication depending on both intrinsic and

14 extrinsic factors. Frogs are widely known for their acoustic signals, which are

15 particularly useful for nocturnal animals. Recently, also the use of visual signals in frog

16 communication has become a focus of research.

17 (2) The first approaches to studying variation in frog colouration dealt mostly with the

18 inheritance of colour patterns. However, not many studies have addressed directly the

19 selective pressures involved in the maintenance of such variation.

20 (3) Dorsal colour patterns can be directly related to predator avoidance. Some frogs

21 blend with their surroundings in different ways such as matching the colouration of their

22 background, exhibiting colour patterns that make it difficult to distinguish their outline

23 the shape, or by resembling an inanimate object. By contrast, other species of frogs

24 display conspicuous colour patterns which are often coupled with some form of

25 unprofitability. Such colour patterns are thought to aid in predator education. Bright 
1 colouration displayed in other parts of the body such as the flanks or ventral side have

2 been much less studied, and their role in predator deterrence is yet to be tested.

3 (4) Cryptically coloured frogs are often polymorphic, which may be favourable as a

4 strategy to reduce the per capita predation risk. The mechanisms that maintain such

5 polymorphisms are still poorly understood, but predation seems to be a good candidate.

6 Aposematic species, on the other hand, are not expected to be polymorphic because

7 intrapopulational variation in warning signals might interfere with predator avoidance

8 learning. Nonetheless, a few aposematic species exhibit colour pattern polymorphisms.

9 Recent research suggests that such polymorphisms could be maintained via an

10 interaction beteween predation and sexual selection, spatio-temporal variation in

11 selection, an association between fitness-related traits and colour patterns, predator

12 generalisation, hybridisation among variants or genetic drift.

13 (5) Experiments in the field with frog models displaying conspicuous colouration have

14 shown the effectiveness of some colour patterns in predator deterrance. With a few

15 exceptions, local morphs tend to be less attacked than novel ones, and moving models

16 exhibiting conspicuous colouration receive fewer attacks than stationary ones.

17 (6) In natural frog populations some palatable species mimic the coloration of defended

18 species, obtaining benefits against predation without investing in the production or

19 sequestration of defensive chemicals (Batesian mimicry). Two (or more) chemically

20 defended species can also share similar colour patterns, thus sharing the costs of

21 predator education (Müllerian mimicry). Only a handful of studies have been able to

22 demonstrate the occurrence of either type of mimicry in anurans, and they have focused

23 only on one taxonomic group.

24 (7) Aposematic individuals are likely to display warning signals that are reliable

25 indicators of their unprofitability, as only defended prey can afford the costs of being 
1 detectable and of having the pigments required for strong warning signals. To

2 demonstrate signal honesty, showing a positive correlation between warning signals and

3 toxicity is not enough. It is necessary to differentiate between quantitative honesty and

4 other ways in which colour patterns and chemical defences can be correlated without

5 involving honest signalling.

6 (8) Colours can have an important role in mate choice, particularly for diurnal species.

7 Interestingly, some species of nocturnal frogs have been shown to pay attention to

8 different components of male colour patterns. This has also been studied extensively in

9 one diurnal species. However, the fitness consequences of female preferences regarding

10 male colouration remain poorly understood.

11 (9) In certain cases, colour patterns may provide information about the social status or

12 fighting abilities of an individual during agonistic encounters. Although this has been

13 shown for the males of some species, there is increasing evidence that colours might

14 play a role in conflict resolution also among females.

15 (10) Besides background matching, habitat selection and space use may also be related

16 to colouration such that different morphs of a species choose a habitat that boosts their

17 conspicuousness. Alternatively, in accordance with the assumed benefits of aggregation

18 of aposematic species, the territories of aposematic frogs might be clumped compared to

19 those of cryptic species. This hypothesis warrants further examination.

20 (11) The detailed study of colour pattern variation, particularly with an experimental

21 approach, should facilitate the formulation and testing of hypotheses on the evolution of

22 predator-prey interactions, mating preferences and communication systems, and provide

23 valuable knowledge on the mechanisms promoting and maintaining signal diversity.

25 VII. ACKNOWLEDGEMENTS 
1 I am deeply grateful to John A. Endler for long and fruitful discussions about animal

2 colouration over recent years, for general encouragement and for comments on early

3 drafts. Many thanks to Johanna Mappes, Swanne Gordon, Jennifer L. Stynoski, Janne

4 Valkonen and two anonymous reviewers for thoughtful suggestions. S. Gordon, J.

5 Stynoski, Laura Kelley and E. Burdfield-Steel provided help with language editing. I

6 thank Jason Brown, Matthew Dugas, Gerardo García, Taran Grant, Trond Larsen, J.P.

7 Lawrence, Roberto Márquez, Quentin Martínez, Mauricio Pacheco, Ralph Saporito,

8 Marc Sztatecsny, Evan Twomey, Marcos Vaira and Alejandro Vélez for kindly sharing

9 their photographs with me.

10

11 VIII. REFERENCES

12 Alatalo, R. V. \& MAPPES, J. (1996). Tracking the evolution of warning signals. Nature $13 \quad 382,708-710$.

14 AlCOCK, J. (2001). Animal behavior: An evolutionary approach. Seventh Edition.

15 Allen, J. A. \& Clarke, B. (1968). Evidence for apostatic selection by wild passerines.

$16 \quad$ Nature 220, 501-502.

17 Allen, J. A. \& GReEnWoOD, J. J. D. (1988). Frequency-dependent selection by

18 predators. Philosophical Transactions of the Royal Society of London B 319 , $19 \quad 485-503$.

20 Alvarado, J. B., Alvarez, A. \& Saporito, R. A. (2013). Oophaga pumilio

21 (Strawberry Poison Frog), Baryphthengus martii (Rufous Motmot). Predator

22 prey interactions. . Herpetological Review 44, 298.

23 Amat, F., Wollenberg, K. C. \& Vences, M. (2013). Correlates of eye colour and

24 pattern in mantellid frogs. Salamandra 49, 7-17. 
1 AmÉzQuita, A. (1999). Color pattern, elevation and body size in the high-Andean frog

2

3

4 Hyla labialis. Revista de la Academia Colombiana de Ciencias Exactas Físicas y Naturales XXIII, 231-238.

Amézquita, A., Castro, L., Arias, M., GonzÁlez, M. \& Esquivel, C. (2013). Field but not lab paradigms support generalisation by predators of aposematic polymorphic prey: the Oophaga histrionica complex. Evolutionary Ecology 27, 769-782.

Amézquita, A., Flechas, S. V., Lima, A. P., Gasser, H. \& Hödl, W. (2011). Acoustic interference and recognition space within a complex assemblage of dendrobatid frogs. Proceedings of the National Academy of Sciences 108, 17058-17063.

Amézquita, A., Lima, A. P., Jehle, R., Castellanos, L., Ramos, O., Crawford, A. J., GASSER, H. \& HoEdL, W. (2009). Calls, colours, shape, and genes: a multi-trait approach to the study of geographic variation in the Amazonian frog Allobates femoralis. Biological Journal of the Linnean Society 98, 826-838.

Andersson, M. (1994). Sexual Selection. Princeton University Press, Princeton, New Jersey.

ANDERSSON, S., ORNBORG, J. \& ANDERSSON, M. (1998). Ultraviolet sexual dimorphism and assortative mating in blue tits. Proceedings of the Royal Society of London B 265, 445-450.

Bajer, K., Molnar, O., Toeroek, J. \& Herczeg, G. (2010). Female European green lizards (Lacerta viridis) prefer males with high ultraviolet throat reflectance. Behavioral Ecology and Sociobiology 64, 2007-2014.

BAJGER, J. (1980). Diversity of defensive responses in populations of fire toads (Bombina bombina and Bombina variegata). Herpetologica 36, 133-137. 
1 Barber, I., Arnott, S. A., Braithwaite, V. A., Andrew, J. \& Huntingford, F. A.

2

3

4

5

6

7

8

9

10

11

12

13

14

15

16

17 (2001). Indirect fitness consequences of mate choice in sticklebacks: offspring of brighter males grow slowly but resist parasitic infections. Proceedings of the Royal Society of London B 268, 71-76.

BAtes, H. W. (1862). Contributions to an insect fauna of the Amazon Valley. Lepidoptera: Heliconidae. 23. Transactions of the Linnean Society of London 23, $495-566$.

BELL, R. C. \& ZAMUdio, K. R. (2012). Sexual dichromatism in frogs: natural selection, sexual selection and unexpected diversity. Proceedings of the Royal Society B 279, $4687-4693$.

Beltrán, M., Jiggins, C. D., Brower, A. V. Z., Bermingham, E. \& Mallet, J. (2007). Do pollen feeding, pupal-mating and larval gregariousness have a single origin in Heliconius butterflies? Inferences from multilocus DNA sequence data. Biological Journal of the Linnean Society 92, 221-239.

BLOUIN, M. S. (1989). Inheritance of a naturally-occurring color polymorphism in the ornate chorus frog, Pseudacris ornata. Copeia, 1056-1059.

Blount, J. D., Rowland, H. M., Drijfhout, F. P., Endler, J. A., Inger, R., Sloggett, J. J., Hurst, G. D. D., Hodgson, D. J. \& Speed, M. P. (2012). How the ladybird got its spots: effects of resource limitation on the honesty of aposematic signals. Functional Ecology 26, 334-342.

Blount, J. D., Speed, M. P., Ruxton, G. D. \& Stephens, P. A. (2009). Warning displays may function as honest signals of toxicity. Proceedings of the Royal Society B 276, 871-877. 
1 Bonansea, M. I. \& VAIRA, M. (2012). Geographic and intrapopulational variation in

2

3

4 colour and patterns of an aposematic toad, Melanophryniscus rubriventris (Amphibia, Anura, Bufonidae). Amphibia-Reptilia 33, 11-24.

Bond, A. B. (2007). The evolution of color polymorphism: Crypticity searching images, and apostatic selection. Annual Review of Ecology Evolution and Systematics 38, 489-514.

Bond, A. B. \& KAMIL, A. C. (1998). Apostatic selection by blue jays produces balanced polymorphism in virtual prey. Nature 395, 594-596.

Bond, A. B. \& KAMIL, A. C. (2006). Spatial heterogeneity, predator cognition, and the evolution of color polymorphism in virtual prey. Proceedings of the National Academy of Sciences 103, 3214-3219.

Borer, M., van NoOrt, T., RAHIER, M. \& NAISBIT, R. E. (2010). Positive frequencydependent selection on warning color in alpine leaf beetles Evolution 64, 36293633.

Born, M., Bongers, F., Poelman, E. H. \& Sterck, F. J. (2010). Dry-season retreat and dietary shift of the dart-poison frog Dendrobates tinctorius (Anura: Dendrobatidae). Phyllomedusa 9, 37-52.

Bourke, J., Busse, K. \& BAKKER, T. C. M. (2011). Sex differences in polymorphic body coloration and dorsal pattern in Darwin's frogs (Rhinoderma darwinii). Herpetological Journal 21, 227-234.

Bradbury, J. W. \& Vehrencamp, S. L. (2011). Principles of Animal Communication, 2nd Edition edition. Sinauer Associates Inc., Sunderland, Massachusetts.

BRODIE, E. D. (1992). Correlational selection for color pattern and antipredator behavior in the garter snake Thamnophis ordinoides. Evolution 46, 1284-1298. 
1 Brusa, O., Bellati, A., Meuche, I., Mundy, N. I. \& Prohl, H. (2013). Divergent

2

3

4

5

6

7

8

9

10

11

12

13

14

15

16

17

18 evolution in the polymorphic granular poison-dart frog, Oophaga granulifera: genetics, coloration, advertisement calls and morphology. Journal of Biogeography 40, 394-408.

Caorsi, V. Z., Colombo, P., Freire, M. D., Amaral, I. B., Zank, C. \& Grant, T. (2014). Natural history, coloration pattern and conservation status of the threatened South Brazilian red bellied toad, Melanophryniscus macrogranulosus Braun, 1973 (Anura, Bufonidae). Herpetology Notes 7, 585-598.

CAPRANICA, R. R. \& MOFFAT, A. J. M. (1983). Neurobehavioral correlates of sound communication in anurans. In Advances in Vertebrate Neuroethology (ed. J. P. Ewert, R. R. Capranica and D. J. Ingle), pp. 701-730. Plenum Press, New York.

CARO, T. (2014). Antipredator deception in terrestrial vertebrates. Current Zoology 60 , $16-25$.

Check, A., Bogart, J. P. \& Lougheed, S. C. (2003). Mating signal partitioning in multi-species assemblages: a null model test using frogs. Ecology Letters 6, 235247.

CHOI, N. \& JANG, Y. (2014). Background matching by means of dorsal color change in treefrog populations (Hyla japonica). Journal of Experimental Zoology A: Ecological Genetics and Physiology 321, 108-118.

Chouteau, M. \& Angers, B. (2011). The role of predators in maintaining the geographic organization of aposematic signals. American Naturalist 178, 810817.

Chouteau, M., Summers, K., Morales, V.\& Angers, B. (2011). Advergence in Mullerian mimicry: the case of the poison dart frogs of Northern Peru revisited. Biology Letters 7, 796-800. 
1 Clark, V. C., Raxworthy, C. J., Rakotomalala, V., Sierwald, P. \& Fisher, B. L.

2

3

4

5

6

7

8

9

10

11

12

13

14

15

16

17 (2005). Convergent evolution of chemical defense in poison frogs and arthropod prey between Madagascar and the Neotropics. Proceedings of the National Academy of Sciences 102, 11617-11622.

Comeault, A. A. \& Noonan, B. P. (2011). Spatial variation in the fitness of divergent aposematic phenotypes of the poison frog, Dendrobates tinctorius. Journal of Evolutionary Biology 24, 1374-1379.

CoOper, W. E., JR., CALDwell, J. P. \& ViTT, L. J. (2008). Effective crypsis and its maintenance by immobility in Craugastor frogs. Copeia, 527-532.

Cotт, H. B. (1940). Adaptive Colouration in Animals. Methuen, London.

Crothers, L., Gering, E. \& Cummings, M. (2011). Aposematic signal variation predicts male-male interactions in a polymorphic poison frog Evolution 65, 599605.

CROTHERS, L. R. \& CUMMINGS, M. E. (2013). Warning signal brightness variation: sexual selection may work under the radar of natural selection in populations of a polytypic poison frog. American Naturalist 181, E116-E124.

Cummings, M. E. \& CROTHERS, L. R. (2013). Interacting selection diversifies warning signals in a polytypic frog: an examination with the strawberry poison frog. Evolutionary Ecology 27, 693-710.

Cuthill, I. C., Stevens, M., Sheppard, J., Maddocks, T., Parraga, C. A. \& Troscianko, T. S. (2005). Disruptive coloration and background pattern matching. Nature 434, 72-74.

Cutrera, A. P., FAnjul, M. S. \& Zenuto, R. R. (2012). Females prefer good genes: MHC-associated mate choice in wild and captive tuco-tucos. Animal Behaviour 83, 847-856. 
1 Daly, J. W., Garraffo, H. M., Hall, G. S. E. \& Cover, J. F., JR. (1997). Absence of

2

3

4

5

6

7

8

9

10

11

12

13

14

15

16

17 skin alkaloids in captive-raised Madagascan mantelline frogs (Mantella) and sequestration of dietary alkaloids. Toxicon $\mathbf{3 5}, 1131-1135$.

Daly, J. W., Garraffo, H. M., Pannell, L. K., Spande, T. F., Severini, C. \& ERSPAMER, V. (1990). Alkaloids from Australian frogs (Myobatrachidae) Pseudophrynamines and pumiliotoxins. Journal of Natural Products 53, 407421.

Daly, J. W., Kaneko, T., Wilham, J., Garraffo, H. M., Spande, T. F., Espinosa, A. \& DonNELly, M. A. (2002). Bioactive alkaloids of frog skin: Combinatorial bioprospecting reveals that pumiliotoxins have an arthropod source. Proceedings of the National Academy of Sciences 99, 13996-14001.

DALY, J. W. \& MYERS, C. W. (1967). Toxicity of Panamanian poison frogs (Dendrobates) - Some biological and chemical aspects. Science 156, 970-\&.

Daly, J. W., Secunda, S. I., Garraffo, H. M., Spande, T. F., Wisnieski, A. \& Cover, J. F., JR. (1994). An uptake system for dietary alkaloids in poison frogs (Dendrobatidae). Toxicon 32, 657-663.

DARst, C. R. \& CuMmings, M. E. (2006). Predator learning favours mimicry of a lesstoxic model in poison frogs. Nature 440, 208-211.

Darst, C. R., Cummings, M. E. \& CAnnatella, D. C. (2006). A mechanism for diversity in warning signals: Conspicuousness versus toxicity in poison frogs. Proceedings of the National Academy of Sciences 103, 5852-5857.

Darst, C. R., Menendez-Guerrero, P. A., Coloma, L. A. \& Cannatella, D. C. (2005). Evolution of dietary specialization and chemical defense in poison frogs (Dendrobatidae): A comparative analysis. American Naturalist 165, 56-69. 
1 DAVISON, J. (1963). Gene action mechanisms in determination of color and pattern in

2

3

4

5

6

7

8

9 frog (Rana pipiens). Science 141, 648-\&.

DE LunA, A. G., HöDL, W. \& AMÉzQuitA, A. (2010). Colour, size and movement as visual subcomponents in multimodal communication by the frog Allobates femoralis. Animal Behaviour 79, 739-745.

Demuth, J. P., NAidu, A. \& MydlarZ, L. D. (2012). Sex, war, and disease: the role of parasite infection on weapon development and mating success in a horned beetle (Gnatocerus cornutus). PLoS One 7, e28690.

Doucet, S. M. \& MenNiLl, D. J. (2010). Dynamic sexual dichromatism in an explosively breeding Neotropical toad. Biology Letters 6, 63-66.

Dreher, C. E., Cummings, M. E. \& PrÖHL, H. (2015). An analysis of predator selection to affect aposematic coloration in a poison frog species PLoS One 10, e 0130571.

Duellman, W. E. \& Pyles, R. E. (1983). Acoustic resource partitioning in anuran communities. Copeia 1983, 639-649.

Duellman, W. E. \& Trueb, L. (1994). Biology of Amphibians. McGraw Hill Publ. Co., New York.

EDMunds, M. (1974). Defence in Animals: A Survey of Antipredator Defences. Longman, New York.

ENDLER, J. A. (1978). A predator's view of animal colour patterns. Evolutionary Biology 11, 319-364.

Endler, J. A. (1980). Natural selection on color patterns in Poecilia reticulata. Evolution 34, 76-91.

ENDLER, J. A. (1984). Progressive background matching in moths, and a quantitative measure of crypsis Biological Journal of the Linnean Society 22, 187-231. 
1 ENDLER, J. A. (1986). Natural selection in the wild. Princeton University Press,

2 Princeton.

3 ENDLER, J. A. (1988). Frequency-dependent predation, crypsis and aposematic

4 coloration Philosophical Transactions of the Royal Society of London B 319,

$5 \quad 505-523$.

6 ENDLER, J. A. (1990). On the measurement and classification of colour in studies of

$7 \quad$ animal colour patterns. Biological Journal of the Linnean Society 41, 315-352.

8 ENDLER, J. A. (1991a). Interactions between predators and prey. In Behavioural

9 Ecology. An evolutionary approach. (ed. J. R. Krebs and N. B. Davies), pp. 169-

10 196. Cambridge University Press, Cambridge.

11 ENDLER, J. A. (1991b). Variation in the appearance of guppy color patterns to guppies

12 and their predators under different visual conditions. Vision Research 31, 587-

608

14 ENDLER, J. A. (1992). Signals, signal condition and the direction of evolution American

$15 \quad$ Naturalist 139, S125-S153.

16 ENDLER, J. A. (1993a). Some general comments on the evolution and design of animal

17 communication systems. Philosophical Transactions of the Royal Society of

$18 \quad$ London B 340, 215-225.

19 ENDLER, J. A. (1993b). The color of light in forests and its implications. Ecological

$20 \quad$ Monographs 63, 1-27.

21 ENDLER, J. A. (2012). A framework for analysing colour pattern geometry: adjacent

22 colours. Biological Journal of the Linnean Society 107, 233-253.

23 Endler, J. A. \& MAPPES, J. (2004). Predator mixes and the conspicuousness of

$24 \quad$ aposematic signals. American Naturalist 163, 532-547. 
1 EndleR, J. A. \& Mielke, P. W. (2005). Comparing entire colour patterns as birds see

2

3

4

5

6

7

8

9 them. Biological Journal of the Linnean Society 86, 405-431.

ENDLER, J. A. \& RoJAs, B. (2009). The spatial pattern of natural selection when selection depends on experience. American Naturalist 173, E62-E78.

ERDTMANn, L. \& AMÉzQUitA, A. (2009). Differential evolution of advertisement call traits in dart-poison frogs (Anura: Dendrobatidae). Ethology 115, 801-811.

EVANS, M. R. \& NORRIS, K. (1996). The importance of carotenoids in signaling during aggressive interactions between male firemouth cichlids (Cichlasoma meeki). Behavioral Ecology 7, 1-6.

Exnerová, A., Svádová , K., Stys, P., Barcalová, S., Landová, E., Prokopovvá, M., FUCHS, R. \& SOCHA, R. (2006). Importance of colour in the reaction of passerine predators to aposematic prey: experiments with mutants of Pyrrhocoris apterus (Heteroptera). Biological Journal of the Linnean Society 88, 143-153.

FARALlo, V. R. \& Forstner, M. R. J. (2012). Predation and the maintenance of color polymorphism in a habitat specialist squamate. PLoS One 7, e30316.

Flores, E. E., Stevens, M., Moore, A. J. \& Blount, J. D. (2013). Diet, development and the optimization of warning signals in post-metamorphic green and black poison frogs. Functional Ecology 27, 816-829.

Fogleman, J. C., Corn, P. S. \& Pettus, D. (1980). The genetic-basis of a dorsal color polymorphism in Rana pipiens. Journal of Heredity 71, 439-440.

FORD, E. B. (1945). Polymorphism. Biological Reviews of the Cambridge Philosophical Society 20, 73-88.

Fraser, S., Callahan, A., Klassen, D. \& Sherratt, T. N. (2007). Empirical tests of the role of disruptive coloration in reducing detectability. Proceedings of the Royal Society B 274, 1325-1331. 
1 Fritz, G., RAND, A. S. \& DePAmphiLis, C. W. (1981). The aposematically colored frog,

2 Dendrobates pumilio, is distasteful to the large, predatory ant, Paraponera

$3 \quad$ clavata. Biotropica 13, 158-159.

4 Fuhrman, F. A., Fuhrman, G. J. \& Mosher, H. S. (1969). Toxin from skin of frogs of the genus Atelopus: differentiation from dendrobatid toxins. Science 165, 13761377.

7 Galarza, J. A., Nokelainen, O., Ashrafi, R., Hegna, R. H. \& Mappes, J. (2014).

8

9

10

11
Temporal relationship between genetic and warning signal variation in the aposematic wood tiger moth (Parasemia plantaginis). Molecular Ecology 23, 4939-4957.

Garraffo, H. M., Caceres, J., Daly, J. W., Spande, T. F., Andriamaharavo, N. R. \& ANDriantsifERANA, M. (1993a). Alkaloids in Madagascan frogs (Mantella). Pumiliotoxins, indolizidines, quinolizidines, and pyrrolizidines. Journal of Natural Products 56, 1016-1038.

Garraffo, H. M., Spande, T. F., Daly, J. W., Baldessari, A. \& Gros, E. G. (1993b). Alkaloids from bufonid toads (Melanophryniscus) - Decahydroquinolines, pumiliotoxins and homopumiliotoxins, indolizidines, pyrrolizidines, and quinolizidines. Journal of Natural Products 56, 357-373.

Gerhardt, H. C. \& HuBer, F. (2002). Acoustic Communication in Insects and Anurans. Common problems and diverse solutions. . The University of Chicago Press, Chicago.

Gomez, D., Richardson, C., Lengagne, T., Derex, M., Plenet, S., Joly, P., Lena, J.P. \& THÉRY, M. (2010). Support for a role of colour vision in mate choice in the nocturnal European treefrog (Hyla arborea). Behaviour 147, 1753-1768. 
1 Gomez, D., Richardson, C., Lengagne, T., Plenet, S., Joly, P., Lena, J.-P. \& ThÉRy,

2

3

4

5

6

7

8

9

10

11

12

13

14

15

16

17

18
M. (2009). The role of nocturnal vision in mate choice: females prefer conspicuous males in the European tree frog (Hyla arborea). Proceedings of the Royal Society B 276, 2351-2358.

Gordon, S. P., Kokko, H., Rojas, B., Nokelainen, O. \& Mappes, J. (2015). Colour polymorphism torn apart by opposing positive frequency-dependent selection, yet maintained in space. Journal of Animal Ecology 84, 1555-1564.

Grant, T., Colombo, P., Verrastro, L. \& SAPORIto, R. A. (2012). The occurrence of defensive alkaloids in non-integumentary tissues of the Brazilian red-belly toad Melanophryniscus simplex (Bufonidae). Chemoecology 22, 169-178.

Gray, H. M. \& Christy, J. H. (2000). Predation by the grapsid crab, Armases angustum (Smith, 1870), on tadpoles of the green poison frog, Dendrobates auratus Girard, 1855. Crustaceana 73, 1023-1025.

Gray, H. M., KAISER, H. \& GreEN, D. M. (2010). Does alkaloid sequestration protect the green poison frog, Dendrobates auratus, from predator attacks? Salamandra 46, 235-238.

GRAY, S. M. \& MCKINNON, J. S. (2007). Linking color polymorphism maintenance and speciation. Trends in Ecology \& Evolution 22, 71-79.

Greenwood, J. J. D., Wood, E. M. \& BATChelor, S. (1981). Apostatic selection of distasteful prey. Heredity 47, 27-34.

GRETHER, G. F. (1996). Intrasexual competition alone favors a sexually dimorphic ornament in the rubyspot damselfly Hetaerina americana. Evolution 50, 19491957.

GuILFORD, T. \& DAWKINS, M. S. (1991). Receiver psychology and the evolution of animal signals. Animal Behaviour 42, 1-14. 
1 GUILFORD, T. \& DAWKINS, M. S. (1993). Are warning colors handicaps? Evolution 47,

2

3

4

5

6

7

8

9

10

11

12

13

14

15

16

17 $400-416$.

HAMilton, W. D. \& ZuK, M. (1982). Heritable true fitness and bright birds -a role for parasites. Science 218, 384-387.

Hantak, M. M., Grant, T., Reinsch, S., MCGinnity, D., Loring, M., TOYOOKA, N. \& SAPORITO, R. A. (2013). Dietary alkaloid sequestration in a poison frog: an experimental test of alkaloid uptake in Melanophryniscus stelzneri (Bufonidae). Journal of Chemical Ecology 39, 1400-1406.

Hegna, R. H., GALARZA, J. A. \& MAPPES, J. (2015). Global phylogeography and geographical variation in warning coloration of the wood tiger moth (Parasemia plantaginis). Journal of Biogeography 42, 1669-1481.

Hegna, R. H., SAPorito, R. A. \& Donnelly, M. A. (2013). Not all colors are equal: predation and color polytypism in the aposematic poison frog Oophaga pumilio. Evolutionary Ecology 27, 831-845.

Hegna, R. H., SAporito, R. A., Gerow, K. G. \& Donnelly, M. A. (2011). Contrasting colors of an aposematic poison frog do not affect predation. Annales Zoologici Fennici 48, 29-38.

HEINDL, M. \& WiNKLER, H. (2003). Interacting effects of ambient light and plumage color patterns in displaying Wire-tailed Manakins (Aves, Pipridae). Behavioral Ecology and Sociobiology 53, 153-162.

HeyING, H. E. (2001). Social and reproductive behaviour in the Madagascan poison frog, Mantella laevigata, with comparisons to the dendrobatids. Animal Behaviour 61, 567-577.

HöDL, W. \& AmÉZquitA, A. (2001). Visual signaling in anuran amphibians. In Anuran Communication. (ed. M. J. Ryan), pp. 121-141. 
1 Hoffman, E. A. \& Blouin, M. S. (2000). A review of colour and pattern polymorphisms in anurans. Biological Journal of the Linnean Society 70, 633-665.

Holen, O. H. \& Svennungsen, T. O. (2012). Aposematism and the handicap principle.

$$
\text { American Naturalist 180, 629-641. }
$$

Hoogmoed, M. \& AvilA-PIRES, T. C. S. (2012). Inventory of color polymorphism in populations of Dendrobates galactonotus (Anura: Dendrobatidae), a poison frog endemic to Brazil. Phyllomedusa 11, 95-115.

Horak, P., Ots, I., Vellau, H., Spottiswoode, C. \& Moller, A. P. (2001). Carotenoid-based plumage coloration reflects hemoparasite infection and local survival in breeding great tits. Oecologia 126, 166-173.

Johnstone, R. A. (1997). The evolution of animal signals. In Behavioural ecology: an evolutionary approach. Fourth edition. (ed. J. R. D. N. B. Krebs), pp. 155-178. Cambridge University Press, Cambridge.

JORON, M. \& MALLET, J. (1998). Diversity in mimicry: paradox or paradigm? Trends in Ecology \& Evolution 13, 461-463.

Karpestam, E., Merilaita, S. \& Forsman, A. (2013). Detection experiments with humans implicate visual predation as a driver of colour polymorphism dynamics in pygmy grasshoppers. BMC Ecology 13.

Karpestam, E., Merilaita, S. \& Forsman, A. (2014). Natural levels of colour polymorphism reduce performance of visual predators searching for camouflaged prey. Biological Journal of the Linnean Society 112, 546-555.

KAUFMANN, J. H. (1983). On the definitions and functions of dominance and territoriality. Biological Reviews of the Cambridge Philosophical Society 58, 120. 
1 Kemp, D. J., Herberstein, M. E., Fleishman, L. J., Endler, J. A., Bennett, A. T. D.,

2

3

4

5

6

7

8

9

10

11

12

13

14

15

16

17

18

19 Dyer, A. G., Hart, N. S., Marshall, J. \& Whiting, M. J. (2015). An integrative framework for the appraisal of coloration in nature. American Naturalist $\mathbf{1 8 5}$, $705-724$.

Kim, Y. H., Kim, Y. B. \& Yotsu-Yamashita, M. (2003). Potent neurotoxins: Tetrodotoxin, chiriquitoxin, and zetekitoxin from Atelopus frogs in Central America. Journal of Toxicology-Toxin Reviews 22, 521-532.

KondRASHOV, A. S. \& SHPAK, M. (1998). On the origin of species by means of assortative mating. Proceedings of the Royal Society of London B 265, 22732278 .

LANCASTER, L. T., Hipsley, C. A. \& Sinervo, B. (2009). Female choice for optimal combinations of multiple male display traits increases offspring survival. Behavioral Ecology 20, 993-999.

Lenger, D. R., Berkey, J. K. \& Dugas, M. B. (2014). Predation on the toxic Oophaga pumilio (Anura: Dendrobatidae) by Rhadinaea decorata (Squamata: Collubridae) Herpetology Notes 7, 83-84.

Lenzi-Mattos, R., M. M. Antoniazzi, M. M., Haddad, C. F. B., TAmbourgi, D. V., RODRIGUeS, M. T. \& JARED, C. (2005). The inguinal macroglands of the frog Physalaemus nattereri (Leptodactylidae): structure, toxic secretion and relationship with deimatic behaviour. Journal of Zoology 266, 385-394.

Lindström, L., Alatalo, R. V., Lyytinen, A. \& Mappes, J. (2001). Strong antiapostatic selection against novel rare aposematic prey. Proceedings of the National Academy of Sciences 98, 9181-9184. 
1 Logue, D. M., Abiola, I. O., Rains, D., Bailey, N. W., ZuK, M. \& Cade, W. H. (2010).

2

3

4

5

6

7

8

9

10 Does signalling mitigate the cost of agonistic interactions? A test in a cricket that has lost its song. Proceedings of the Royal Society B 277, 2571-2575.

LóPez, P., MARTin, J. \& CUAdrado, M. (2004). The role of lateral blue spots in intrasexual relationships between male Iberian rock-lizards, Lacerta monticola. Ethology 110, 543-561.

LorenZ, K. (1966). On Aggression. Methuen \& Co. Ltd., London.

LOSOS, J. B. \& CHU, L.-R. (1998). Examination of factors potentially affecting dewlap size in Caribbean anoles. Copeia 1998, 430-438.

Lötters, S., Castro-Herrera, F., KöHLER, J. \& Richter, R. (1997). Notes on the distribution and color variation of poison frogs of the genus Phyllobates from western Colombia (Anura: Dendrobatidae). Revue Française d'Aquariologie 24, $55-58$.

Lötters, S., Jungfer, K.-H., Henkel, F. W. \& Schmidt, W. (2007). Poison frogs: biology, species and captive husbandry. Edition Chimaira.

Lüddecke, H., AmÉzquita, A., Bernal, X. \& Guzman, F. (2000). Partitioning of vocal activity in a Neotropical highland-frog community. Studies on Neotropical Fauna and Environment 35, 185-194.

MAAn, M. E. \& CUMmingS, M. E. (2008). Female preferences for aposematic signal components in a polymorphic poison frog. Evolution 62, 2334-2345.

MaAn, M. E. \& Cummings, M. E. (2009). Sexual dimorphism and directional sexual selection on aposematic signals in a poison frog. Proceedings of the National Academy of Sciences 106, 19072-19077.

MaAn, M. E. \& Cummings, M. E. (2012). Poison frog colors are honest signals of toxicity, particularly for bird predators. American Naturalist 179, E1-E14. 
1 MaAn, M. E. \& Seehausen, O. (2011). Ecology, sexual selection and speciation.

2

3

4

5

6

7

8

9

10

11

12

13

14

15

16

17

18

19 Ecology Letters 14, 591-602.

MaAn, M. E., Seehausen, O., Soderberg, L., Johnson, L., Ripmeester, E. A. P., Mrosso, H. D. J., TAYlor, M. I., van Dooren, T. J. M. \& van Alphen, J. J. M. (2004). Intraspecific sexual selection on a speciation trait, male coloration, in the Lake Victoria cichlid Pundamilia nyererei. Proceedings of the Royal Society of London B 271, 2445-2452.

MAHER, C. R. \& LOTT, D. F. (1995). Definitions of territoriality used in the study of variation in vertebrate spacing systems. Animal Behaviour 49, 1581-1597.

MALLET, J. \& JORON, M. (1999). Evolution of diversity in warning color and mimicry: Polymorphisms, shifting balance, and speciation. Annual Review of Ecology and Systematics 30, 201-233.

Mappes, J. \& Alatalo, R. V. (1997). Effects of novelty and gregariousness in survival of aposematic prey. Behavioral Ecology 8, 174-177.

MAPPES, J., MARPLES, N. \& ENDLER, J. A. (2005). The complex business of survival by aposematism. Trends in Ecology \& Evolution 20, 598-603.

Martins, M. (1989). Deimatic Behavior in Pleurodema brachyops. Journal of Herpetology 23, 305-307.

MASTER, T. L. (1999). Predation by Rufous Motmot on black-and-green poison dart frog. Wilson Bulletin 111, 439-440.

MAYNARD SMITH, J. (1982). Evolution and the Theory of Games. Cambridge University Press, Cambridge, UK.

Maynard Smith, J. \& HarPer, D. G. C. (2005). Animal Signals. Oxford University Press, Oxford, UK. 
1 Medina, I., Wang, I. J., SAlazAr, C. \& AmÉzQuita, A. (2013). Hybridization promotes

2

3

4 5 color polymorphism in the aposematic harlequin poison frog, Oophaga histrionica. Ecology and Evolution 3, 4388-4400.

Melo, M. C., Salazar, C., Jiggins, C. D. \& Linares, M. (2009). Assortative mating preferences among hybrids offers a route to hybrid speciation. Evolution 63, $1660-1665$.

Meuche, I., Linsenmair, K. E. \& Proehl, H. (2011). Female Territoriality in the Strawberry Poison Frog (Oophaga pumilio). Copeia 2011, 351-356.

MiLinSKI, M. \& BAKKER, T. C. M. (1990). Female sticklebacks use male coloration in mate choice and hence avoid parasitized males. Nature 344, 330-333.

MokKonen, M. \& LindstedT, C. (2015). The evolutionary ecology of deception. Biological Reviews DOI: 10.1111/brv.12208.

MoREY, S. R. (1990). Microhabitat selection and predation in the Pacific treefrog, Pseudacris regilla. Journal of Herpetology 24, 292-296.

Morimoto, G., Yamaguchi, N. \& UedA, K. (2005). Plumage color as a status signal in male-male interaction in the red-flanked bushrobin, Tarsiger cyanurus. Journal of Ethology 24, 261-266.

MÜLlER, F. (1878). Ueber die Vortheile der Mimicry bei Schmetterlingen Zoologischer Anzeiger 1, 54-55.

Munday, P. L., Eyre, P. J. \& Jones, G. P. (2003). Ecological mechanisms for coexistence of colour polymorphism in a coral-reef fish: an experimental evaluation. Oecologia 137, 519-526.

Myers, C. W. \& DALY, J. W. (1976). Preliminary evaluation of skin toxins and vocalizations in taxonomic and evolutionary studies of poison-dart frogs 
(Dendrobatidae). Bulletin of the. American. Museum of Natural History 157, $177-262$.

3 Myers, C. W. \& DALY, J. W. (1983). Dart-poison frogs. Scientific American 248, 96-

4

5

6

7

8 105.

Myers, C. W., Daly, J. W. \& Malkin, B. (1978). A dangerously toxic new frog (Phyllobates) used by Emberá indians of western Colombia, with discussion of blowgun fabrication and dart poisoning. Bulletin of the American Museum of Natural History 161, 309-365.

NARINS, P. M., HÖDL, W. \& GRABUL, D. S. (2003). Bimodal signal requisite for agonistic behavior in a dart-poison frog, Epipedobates femoralis. Proceedings of the National Academy of Sciences 100, 577-580.

Nevo, E. (1973). Adaptive color polymorphism in cricket frogs. Evolution 27, 353-367.

Nokelainen, O., Hegna, R. H., Reudler, J. H., Lindstedt, C. \& MAPPes, J. (2012). Trade-off between warning signal efficacy and mating success in the wood tiger moth. Proceedings of the Royal Society B 279, 257-265.

Nokelainen, O., Lindstedt, C. \& MAPPES, J. (2013). Environment-mediated morphlinked immune and life-history responses in the aposematic wood tiger moth. Journal of Animal Ecology 82, 653-662.

Nokelainen, O., VAlkonen, J., Lindstedt, C. \& MAPpes, J. (2014). Changes in predator community structure shifts the efficacy of two warning signals in Arctiid moths. Journal of Animal Ecology 83, 598-605.

NoOnan, B. P. \& Comeault, A. A. (2009). The role of predator selection on polymorphic aposematic poison frogs. Biology Letters 5, 51-54.

NoOnan, B. P. \& GAUChER, P. (2006). Refugial isolation and secondary contact in the dyeing poison frog Dendrobates tinctorius. Molecular Ecology 15, 4425-4435. 
1 O'Donald, P. \& Majerus, M. E. N. (1984). Polymorphism of melanic ladybirds

2

3

4

5

6

7

8

9

10

11

12

13

14

15

16

17

18

19 maintained by frequency-dependent sexual selection. Biological Journal of the Linnean Society 23, 101-111.

OLSSON, M. (1994). Nuptial coloration in the sand lizard, Lacerta agilis: an intrasexually selected cue to fighting ability. Animal Behaviour 48, 607-613.

ORD, T. J. \& EVANS, C. S. (2003). Display rate and opponent assessment in the Jacky dragon (Amphibolurus muricatus): an experimental analysis. Behaviour 140, $1495-1508$.

OSORIO, D. \& SRINIVASAN, M. V. (1991). Camouflage by edge enhancement in animal coloration patterns and its implications for visual mechanisms. Proceedings of the Royal Society B 244, 81-85.

Paluh, D. J., HANTAK, M. M. \& SAPORIto, R. A. (2014). A test of aposematism in the dendrobatid poison frog Oophaga pumilio: the importance of movement in clay model experiments. Journal of Herpetology 48, 249-254.

Pellissier, L., Wassef, J., Bilat, J., Brazzola, G., Buri, P., Colliard, C., Fournier, B., Hausser, J., YAnnic, G. \& Perrin, N. (2011). Adaptive colour polymorphism of Acrida ungarica $\mathrm{H}$. (Orthoptera: Acrididae) in a spatially heterogeneous environment. Acta Oecologica-International Journal of Ecology 37, 93-98.

Petrie, M., Halliday, T. \& SANDERS, C. (1991). Peahens prefer peacocks with elaborate trains. Animal Behaviour 41, 323-331.

Pincemy, G., DobSON, F. S. \& Jouventin, P. (2009). Experiments on colour ornaments and mate choice in king penguins. Animal Behaviour 78, 1247-1253.

Pough, F. H., Andrews, R. M., CAdle, J. E., Crump, M. L., SAvitzky, A. L. \& Wells, K. D. (2001). Herpetology. Prentice Hall, Upper Saddle River, New Jersey. 
1 Poulton, E. B. (1890). The Colours of Animals: Their Meaning and Use. Kegan Paul, 2 Trench, Trubner, London.

3 Prates, I., Antoniazzi, M. M., Sciani, J. M., Pimenta, D. C., Toledo, L. F., Haddad,

4 C. F. B. \& JARED, C. (2012). Skin glands, poison and mimicry in dendrobatid and 5 leptodactylid amphibians. Journal of Morphology 273, 279-290.

6 PRÖHL, H. (2005). Territorial behavior in dendrobatid frogs. Journal of Herpetology 39, 7 354-365.

8 PRÖHL, H. \& OstrowsKI, T. (2011). Behavioural elements reflect phenotypic colour 9 divergence in a poison frog. Evolutionary Ecology 25, 993-1015.

10 PRYKE, S. R. \& ANDERSSON, S. (2003a). Carotenoid-based epaulettes reveal male 11 competitive ability: experiments with resident and floater red-shouldered 12 widowbirds. Animal Behaviour 66, 217-224.

13 Pryke, S. R. \& ANDERsson, S. (2003b). Carotenoid-based status signalling in red14 shouldered widowbirds (Euplectes axillaris): epaulet size and redness affect 15 captive and territorial competition. Behavioral Ecology and Sociobiology 53, $16 \quad 393-401$.

17 PRYKe, S. R. \& GRIFFITH, S. C. (2006). Red dominates black: agonistic signalling among 18 head morphs in the colour polymorphic Gouldian finch. Proceedings of the $19 \quad$ Royal Society B 273, 949-957.

20 Renoult, J. P., Kelber, A. \& Schaefer, H. M. (2015). Colour spaces in ecology and 21 evolutionary biology. Biological Reviews, DOI: 10.1111/brv.12230.

22 ResniCK, L. E. \& JAMESON, D. L. (1963). Color polymorphism in Pacific tree frogs. Science 142, 1081-\&.

24 REYNOLDS, R. G. \& FitZPATRICK, B. M. (2007). Assortative mating in poison-dart frogs 25 based on an ecologically important trait. Evolution 61, 2253-2259. 
1 Richards-Zawacki, C. L., Wang, I. J. \& Summers, K. (2012). Mate choice and the

2

3

4 genetic basis for colour variation in a polymorphic dart frog: inferences from a wild pedigree. Molecular Ecology 21, 3879-3892.

Richards-ZaWACKI, C. L., YeAger, J. \& BART, H. P. S. (2013). No evidence for differential survival or predation between sympatric color morphs of an aposematic poison frog. Evolutionary Ecology 27, 783-795.

RIECHERT, S. E. (1998). Game theory and animal contests. In Game Theory and Animal Behavior. (ed. L. A. R. H. K. Dugatkin), pp. 64-93. Oxford University Press, Oxford.

RiIPI, M., Alatalo, R. V., Lindstrom, L. \& Mappes, J. (2001). Multiple benefits of gregariousness cover detectability costs in aposematic aggregations. Nature 413, $512-514$.

Ringler, M., URSPRUnG, E. \& HöDL, W. (2010). Predation on Allobates femoralis (Boulenger 1884; Anura: Aromobatidae) by the colubrid snake Xenopholis scalaris (Wucherer 1861). Herpetology Notes 3, 301-304.

Rojas, B., Devillechabrolle, J. \& Endler, J. A. (2014a). Paradox lost: variable colour-pattern geometry is associated with differences in movement in aposematic frogs. Biology Letters 10, 20140193.

RoJAs, B. \& ENDLER, J. A. (2013). Sexual dimorphism and intra-populational colour pattern variation in the aposematic frog Dendrobates tinctorius. Evolutionary Ecology 27, 739-753.

ROJAS, B., GORDON, S. P. \& MAPPES, J. (2015a). Frequency-dependent flight activity in the colour polymorphic wood tiger moth. Current Zoology 61, 765-772. 
1 Rojas, B., RaUtiala, P. \& MAPPES, J. (2014b). Differential detectability of polymorphic

2

3

4

5

6

7

8

9 warning signals under varying light environments Behavioural Processes 109, 164-172.

Rojas, B., Valkonen, J. K. \& Nokelainen, O. (2015b). Aposematism. Current Biology 25, R350-R351.

Rudh, A., Breed, M. F. \& Qvarnstrom, A. (2013). Does aggression and explorative behaviour decrease with lost warning coloration? Biological Journal of the Linnean Society 108, 116-126.

RUDH, A. \& QVARnSTRÖM, A. (2013). Adaptive colouration in Amphibians. Seminars in Cell \& Developmental Biology 24, 553-561.

Ruxton, G. D., Sherratt, T. N. \& Speed, M. P. (2004). Avoiding Attack: the evolutionary ecology of crypsis, warning signals and mimicry. Oxford University Press, Oxford.

Santos, J. C. \& CANNATElla, D. C. (2011). Phenotypic integration emerges from aposematism and scale in poison frogs. Proceedings of the National Academy of Sciences 108, 6175-6180.

Santos, J. C., Coloma, L. A. \& CAnNAtella, D. C. (2003). Multiple, recurring origins of aposematism and diet specialization in poison frogs. Proceedings of the National Academy of Sciences 100, 12792-12797.

SANTOS, R. R. \& GRANT, T. (2011). Diel pattern of migration in a poisonous toad from Brazil and the evolution of chemical defenses in diurnal amphibians. Evolutionary Ecology 25, 249-258.

Saporito, R. A., Donnelly, M. A., Norton, R. A., GARraffo, H. M., SPAnde, T. F. \& DALY, J. W. (2007a). Oribatid mites as a major dietary source for alkaloids in poison frogs. Proceedings of the National Academy of Sciences 104, 8885-8890. 
1 Saporito, R. A., Donnelly, M. A., Spande, T. F. \& Garraffo, H. M. (2012). A review

2

3

4

5

6

7

8

9

10

11

12 of chemical ecology in poison frogs. Chemoecology 22, 159-168.

SAPorito, R. A., Garraffo, H. M., Donnelly, M. A., Edwards, A. L., Longino, J. T. \& DALY, J. W. (2004). Formicine ants: An arthropod source for the pumiliotoxin alkaloids of dendrobatid poison frogs. Proceedings of the National Academy of Sciences 101, 8045-8050.

Saporito, R. A., Zuercher, R., Roberts, M., Gerow, K. G. \& Donnelly, M. A. (2007b). Experimental evidence for aposematism in the dendrobatid poison frog Oophaga pumilio. Copeia 2007, 1006-1011.

Saviola, A. J., McKenzie, V. J. \& Chiszar, D. (2012). Chemosensory responses to chemical and visual stimuli in five species of colubrid snakes. Acta Herpetologica 7, 91-103.

Schaefer, H. C., Vences, M. \& VeIth, M. (2002). Molecular phylogeny of Malagasy poison frogs, genus Mantella (Anura : Mantellidae): homoplastic evolution of colour pattern in aposematic amphibians. Organisms Diversity \& Evolution 2, 97-105.

SCHAEFER, H. M. (2010). Visual communication: evolution, ecology, and functional mechanisms. In Animal Behaviour: Evolution and Mechanisms (ed. P. Kappeler), pp. 3-28.

Sebben, A., Schwartz, C. A., Valente, D. \& Mendes, E. G. (1986). A tetrodotoxinlike substance found in the Brazilian frog Brachycephalus ephippium. Toxicon 24, 799-806.

Seehausen, O. \& Van Alphen, J. J. M. (1998). The effect of male coloration on female mate choice in closely related Lake Victoria cichlids (Haplochromis nyererei complex). Behavioral Ecology and Sociobiology 42, 1-8. 
1 Sheldon, B. C., Arponen, H., Laurila, A., Crochet, P. A. \& Merila, J. (2003). Sire

2

3

4 coloration influences offspring survival under predation risk in the moorfrog. Journal of Evolutionary Biology 16, 1288-1295.

Sherratt, T. N. (2002). The coevolution of warning signals. Proceedings of the Royal Society of London B 269, 741-746.

Siddiqi, A., Cronin, T. W., Loew, E. R., Vorobyev, M. \& Summers, K. (2004). Interspecific and intraspecific views of color signals in the strawberry poison frog Dendrobates pumilio. Journal of Experimental Biology 207, 2471-2485.

SILLÉN-TULLBERG, B. (1988). Evolution of gregariousness in aposematic butterfly larvae: A phylogenetic analysis. Evolution 42, 293-305.

Silverstone, P. A. (1975). A revision of the poison-arrow frogs of the genus Dendrobates Wagler. Natural History Museum of Los Angeles County Science Bulletin 21, 1-55.

SinerVo, B. \& SVEnSSON, E. (2002). Correlational selection and the evolution of genomic architecture. Heredity 89, 329-338.

Skelhorn, J., Rowland, H. M., SPeed, M. P. \& RuXton, G. D. (2010). Masquerade: Camouflage Without Crypsis. Science 327, 51.

Sommer, V. (1987). Infanticide among free-ranging langurs (Presbytis entellus) at Jodhpur (Rajasthan India) - Recent observations and a reconsideration of hypotheses. Primates 28, 163-197.

SPEED, M. P. (2000). Warning signals, receiver psychology and predator memory. Animal Behaviour 60, 269-278.

Stange, N. \& Ronacher, B. (2012). Grasshopper calling songs convey information about condition and health of males. Journal of Comparative Physiology A 198, 309-318. 
1 Starnberger, I., Preininger, D. \& HöDl, W. (2014). From uni- to multimodality:

2

3

4 5 towards an integrative view on anuran communication. Journal of Comparative Physiology A 200, 777-787.

Stevens, M. \& Merilaita, S. (2009). Animal camouflage: current issues and new perspectives. Philosophical Transactions of the Royal Society B 364, 423-427.

StUART, Y. E., DAPPEN, N. \& LOSIN, N. (2012). Inferring predator behavior from attack rates on prey-replicas that differ in conspicuousness. PLoS One 7, e40497.

Stuart-Fox, D. M. \& Johnston, G. R. (2005). Experience overrides colour in lizard contests. Behaviour 142, 329-350.

Stuckert, A. M. M., SAPorito, R. A., Venegas, P. J. \& Summers, K. (2014a). Alkaloid defenses of co-mimics in a putative Mullerian mimetic radiation. BMC Evolutionary Biology 14, 76.

Stuckert, A. M. M., Venegas, P. J. \& Summers, K. (2014b). Experimental evidence for predator learning and Müllerian mimicry in Peruvian poison frogs (Ranitomeya, Dendrobatidae). Evolutionary Ecology 28, 413-426.

Stynoski, J. L., Shelton, G. \& StYnoski, P. (2014). Maternally derived chemical defences are an effective deterrent against some predators of poison frog tadpoles (Oophaga pumilio). Biology Letters 10, 20140187.

SUMMERS, K. (1989). Sexual selection and intra-female competition in the green poisondart frog, Dendrobates auratus. Animal Behaviour 37, 797-805.

SuMmERs, K. (1992). Mating strategies in two species of dart-poison frogs: a comparative study. Animal Behaviour 43, 907-919.

SumMERS, K. (2003). Convergent evolution of bright coloration and toxicity in frogs. Proceedings of the National Academy of Sciences 100, 12533-12534. 
1 Summers, K., Bermingham, E., Weigt, L. \& McCafferty, S. (1997). Phenotypic and

2

3

4 5 genetic divergence in three species of dart-poison frogs with contrasting parental behavior. Journal of Heredity 88, 8-13.

Summers, K. \& Clough, M. E. (2001). The evolution of coloration and toxicity in the poison frog family (Dendrobatidae). Proceedings of the National Academy of Sciences 98, 6227-6232.

Summers, K., Speed, M. P., Blount, J. D. \& Stuckert, A. M. M. (2015). Are aposematic signals honest? A review. Journal of Evolutionary Biology 28, 1583 1599.

Summers, K., Symula, R., Clough, M. \& Cronin, T. (1999). Visual mate choice in poison frogs. Proceedings of the Royal Society of London B 266, 2141-2145.

Symula, R., Schulte, R. \& Summers, K. (2001). Molecular phylogenetic evidence for a mimetic radiation in Peruvian poison frogs supports a Mullerian mimicry hypothesis. Proceedings of the Royal Society of London B 268, 2415-2421.

SzELISTOWSKI, W. A. (1985). Unpalatability of the poison arrow frog Dendrobates pumilio to the ctenid spider Cupiennius coccineus. Biotropica 17, 345-346.

Sztatecsny, M., Preininger, D., Freudmann, A., Loretto, M.-C., Maier, F. \& HöDL, W. (2012). Don't get the blues: conspicuous nuptial colouration of male moor frogs (Rana arvalis) supports visual mate recognition during scramble competition in large breeding aggregations. Behavioral Ecology and Sociobiology 66, 1587-1593.

Sztatecsny, M., Strondl, C., BAierl, A., Ries, C. \& HöDl, W. (2010). Chin up: are the bright throats of male common frogs a condition-independent visual cue? Animal Behaviour 79, 779-786. 
1 Stynoski, J. L., Schulte, L. M. \& Rojas, B. 2015. Poison frogs. Current Biology 25,

2

3

4 R1026-R1028.

TAYlor, R. C., Klein, B. A., Stein, J. \& Ryan, M. J. (2011). Multimodal signal variation in space and time: how important is matching a signal with its signaler? Journal of Experimental Biology 214, 815-820.

Terai, Y. \& OKadA, N. (2011). Speciation of Cichlid Fishes by Sensory Drive. In From Genes to Animal Behavior: Social Structures, Personalities, Comminication by Color. Primatology Monographs (ed. M. K. S. W. A. InoueMurayama), pp. 311328.

Thayer, G. H. (1909). Concealing Coloration in the Animal Kingdom. An Exposition of the Laws of Disguise through Color and Pattern; Being a Summary of Abbott H. Thayer's Discoveries Macmillan, New York.

THÉry, M. (2001). Forest light and its influence on habitat selection. Plant Ecology 153, 251-261.

THÉRY, M. \& ENDLER, J. A. (2001). Habitat selection, ambient light and colour patterns in some lek-displaying birds. In Nouragues: dynamics and plant-animal interactions in a neotropical rainforest., vol. 80 (ed. F. Bongers, P. CharlesDominique, P.-M. Forget and M. Théry), pp. 161-166. Kluwer Academic Publisher, Dordrecht, The Netherlands.

ThOMPson, V. (1984). Polymorphism under apostatic and aposematic selection. Heredity 53, 677-686.

TOFT, C. A. (1995). Evolution of diet specialization in poison-dart frogs (Dendrobatidae). Herpetologica 51, 202-216.

Toledo, L. F. \& HADDAD, C. F. B. (2009). Colors and some morphological traits as defensive mechanisms in anurans. International Journal of Zoology 2009, 1-12. 
1 Tordoff, W. (1980). Selective predation of gray jays, Perisoreus canadensis, upon

$2 \quad$ boreal chorus frogs, Pseudacris triseriata. Evolution 34, 1004-1008.

3 TwOmey, E., VestergaArD, J. S. \& SuMmers, K. (2014). Reproductive isolation related

4 to mimetic divergence in the poison frog Ranitomeya imitator. Nature

5 Communications 5, 4749.

6 Twomey, E., Yeager, J., Brown, J. L., Morales, V., Cummings, M. \& Summers, K. 7

Umbers, K. D. L., Lehtonen, J. \& MAPPes, J. (2015). Deimatic displays. Current Biology 25, R58-R59.

VAlkonen, J., Niskanen, M., Bjorklund, M. \& MapPes, J. (2011). Disruption or aposematism? Significance of dorsal zigzag pattern of European vipers. Evolutionary Ecology 25, 1047-1063.

Valkonen, J. K., NoKelainen, O., Niskanen, M., KilpimaA, J., BJorklund, M. \& MAPPES, J. (2012). Variation in predator species abundance can cause variable selection pressure on warning signaling prey. Ecology and Evolution 2, 19711976.

VAsqueZ, T. \& PfENNIG, K. S. (2007). Looking on the bright side: females prefer coloration indicative of male size and condition in the sexually dichromatic spadefoot toad, Scaphiopus couchii. Behavioral Ecology and Sociobiology 62, 127-135. 
1 Veith, M., Kosuch, J., Roedel, M.-O., Hillers, A., Schmitz, A., Burger, M. \&

2

3

4 5

6 7

8

9

10

11

12

13

14

15

16 LÖTTERS, S. (2009). Multiple evolution of sexual dichromatism in African reed frogs. Molecular Phylogenetics and Evolution 51, 388-393.

Vences, M., Kosuch, J., Boistel, R., Haddad, C. F. B., La Marca, E., LotTers, S. \& Veith, M. (2003). Convergent evolution of aposematic coloration in Neotropical poison frogs: a molecular phylogenetic perspective. Organisms Diversity \& Evolution 3, 215-226.

VorobyeV, M. \& OSORIO, D. (1998). Receptor noise as a determinant of colour thresholds. Proceedings of the Royal Society B 265, 351-358.

Vorobyev, M., Osorio, D., Bennett, A. T. D., Marshall, N. J. \& Cuthill, I. C. (1998). Tetrachromacy, oil droplets and bird plumage colours. Journal of Comparative Physiology A-Neuroethology Sensory Neural and Behavioral Physiology 183, 621-633.

Wallace, A. R. (1877). The colours of animals and plants. American Naturalist 11, $641-662$.

WANG, I. J. (2011). Inversely related aposematic traits: reduced conspicuousness evolves with increased toxicity in a polymorphic poison-dart frog. Evolution 65, 16371649.

WELLS, K. D. (1978). Courtship and parental behavior in a Panamanian poison-arrow frog (Dendrobates auratus). Herpetologica 34, 148-155.

WeLLS, K. D. (1980). Social behavior and communication of a dendrobatid frog (Colostethus trinitatis). Herpetologica 36, 189-199.

WeLLS, K. D. (2007). The Ecology and Behavior of Amphibians. University of Chicago Press, Chicago. 
1 Wente, W. H. \& Phillips, J. B. (2005). Microhabitat selection by the Pacific treefrog, 2 Hyla regilla. Animal Behaviour 70, 279-287.

3 Whiting, M. J., Stuart-Fox, D. M., O'Connor, D., Firth, D., Bennett, N. C. \&

4 BlomberG, S. P. (2006). Ultraviolet signals ultra-aggression in a lizard. Animal Behaviour 72, 353-363.

WILEY, R. H. (1983). The evolution of communication: information and manipulation. In Animal Behaviour Vol. 2: Communication (ed. T. R. Halliday and P. B. J. Slater), pp. 156-189. Blackwell Scientific Publications, Oxford.

WILEY, R. H. (1994). Errors, exaggeration, and deception in animal communication. In Behavioral Mechanisms in Ecology (ed. L. A. Real), pp. 157-189. University of Chicago Press, Chicago.

Willink, B., Brenes-Mora, E., Bolaños, F. \& PrÖHL, H. (2013). Not everything is black and white: color and behavioral variation reveal a continuum between cryptic and aposematic strategies in a polymorphic poison frog. Evolution 67, $2783-2794$.

Wollenberg, K. C., Lötters, S., Mora-Ferrer, C. \& Veith, M. (2008). Disentangling composite colour patterns in a poison frog species. Biological Journal of the Linnean Society 93, 433-444.

Woolbright, L. L. \& STEWART, M. M. (2008). Spatial and temporal variation in color pattern morphology in the tropical frog, Eleutherodactylus coqui. Copeia, 431437.

Yeager, J., Brown, J. L., Morales, V., Cummings, M. \& Summers, K. (2012). Testing for selection on color and pattern in a mimetic radiation. Current Zoology 58, $668-676$. 
1

2

3

4

5

6

7

8

9

10

11

12

13

14

15

16

17

18

19

20

21

22

23

24

25

26

27

28

29

30

31

32

33

34

35

36

37

38

39

40

41

42

43

44

45

46

47

48

49

50

51

52

53

54

55

56

57

58

59

60

1 ZAHAVI, A. (1975). Mate selection—a selection for a handicap. Journal of Theoretical

$2 \quad$ Biology 53, 205-214.

3 ZIMMERMANN, H. \& ZIMMERMANN, E. (1988). Etho-Taxonomie und zoogeographische

4 Artengruppenbildung bei Pfeilgiftfröschen (Anura: Dendrobatidae). Salamandra

$5 \quad 24,125-160$. 
2 Figure legends

3

4 Fig. 1. An example of background matching in a young Pristimantis zeuctotylus (A);

5 and examples of masquerading, where a female Rhinella margaritifera is shown to

6 resemble a dead leaf (B-D). Images $\mathrm{C}$ and D are for the same individual photographed

7 at different distances. Photo credits: Bibiana Rojas.

8

9 Fig. 2. Aposematic frogs (A) Mantella baroni; (B) Mantella aurantiaca; (C) Dyscophus

10 guineti, known as the 'Tomato frog'; (D) Pseudophryne corroboree; (E)

11 Brachycephalus ephippium; and (F) Melanophryniscus rubriventris. Photo credits: A-C,

12 Gerardo García; D, J.P. Lawrence; E, Taran Grant; F, Marcos Vaira.

13

14 Fig. 3. Atelopus aff. franciscus (A) dorsal and (B) ventral colouration. (C) Geographic

15 variation in the dorsal and ventral colouration of Melanophryniscus rubriventris. Photo

16 credits: A,B, Bibiana Rojas; C, Marcos Vaira.

18 Fig. 4. Dart poison frogs represent the best-known example of aposematism among

19 anurans. (A) Adelphobates galactonotus; (B) Ameerega bilinguis; (C) Dendrobates

20 truncatus; (D) Dendrobates tinctorius; (E) Phyllobates terribilis; (F) Dendrobates

21 auratus; (G) Oophaga granulifera; (H) Phyllobates lugubris and (I) Ranitomeya

22 imitator. Photo credits: A,C, Taran Grant; B,F,H,I, J.P. Lawrence; D,G, Bibiana Rojas;

23 E, Roberto Márquez. 
1 Fig. 5. Known predators of dendrobatid frogs: (A) the snake Rhadinaea decorata,

2 feeding on Oophaga pumilio; (B) wolf spider (Lycosidae) preying on Ameerega

3 trivittata; (C) crab holding an individual Oophaga histrionica; (D) rufous motmot

4 (Baryphthengus martii) taking an O. pumilio to its nest. Photo credits: A, Matthew

5 Dugas; B, Trond Larsen; C, Alejandro Vélez; D, Ralph Saporito.

7 Fig. 6. Examples of mimicry among poison frog species. (A) Ameerega hahneli (left) is

8 thought to be a model for Allobates femoralis (right); Leptodactylus lineatus (C) has

9 been suggested to be a Müllerian mimic of Ameerega picta (B). The best-known case of

10 a Müllerian mimicry system is that of Ranitomeya imitator. D-G are the model species:

11 Ranitomeya variabilis, highland morph; $R$. summersi, $R$. fantastica, $R$. variabilis

12 lowland morph. The different morphs of $R$. imitator are shown below: (H) spotted; (I)

13 banded; (J) varadero; and (K) striped. Photo credits: A, Jason L. Brown; B, Mauricio

14 Pacheco; C, Quentin Martínez; D-K Evan Twomey.

15

16 Fig. 7. Examples of geographic variation in the colour patterns of Oophaga pumilio (A-

17 D); and intrapopulation variation in Dendrobates tinctorius (E-H). Photo credits: A-D,

18 J.P. Lawrence; E-H, Bibiana Rojas.

20 Fig. 8. Flash colouration in the flanks of Phyllomedusa tomopterna (A); 'eye spots' in 21 the lower dorsum of Edalorhina perezi (B); and (C-E) the 'unken reflex' performed by 22 species of the genus Melanophryniscus, even in amplexus (D). All have been suggested 23 to function as deimatic displays. Photo credits: A,B, J.P. Lawrence; C,D, Marcos Vaira; 24 E, Taran Grant. 
1 Fig. 9. Breeding aggregation of Rana temporaria (A) and a pair of the moor frog (Rana

2 arvalis) in amplexus (B). Note the bright throats and blue colouration of the males,

3 which are thought to function as sex-recognition cues to prevent mismatings. Photo

4 credits: Marc Sztatecsny.

5

6

7 

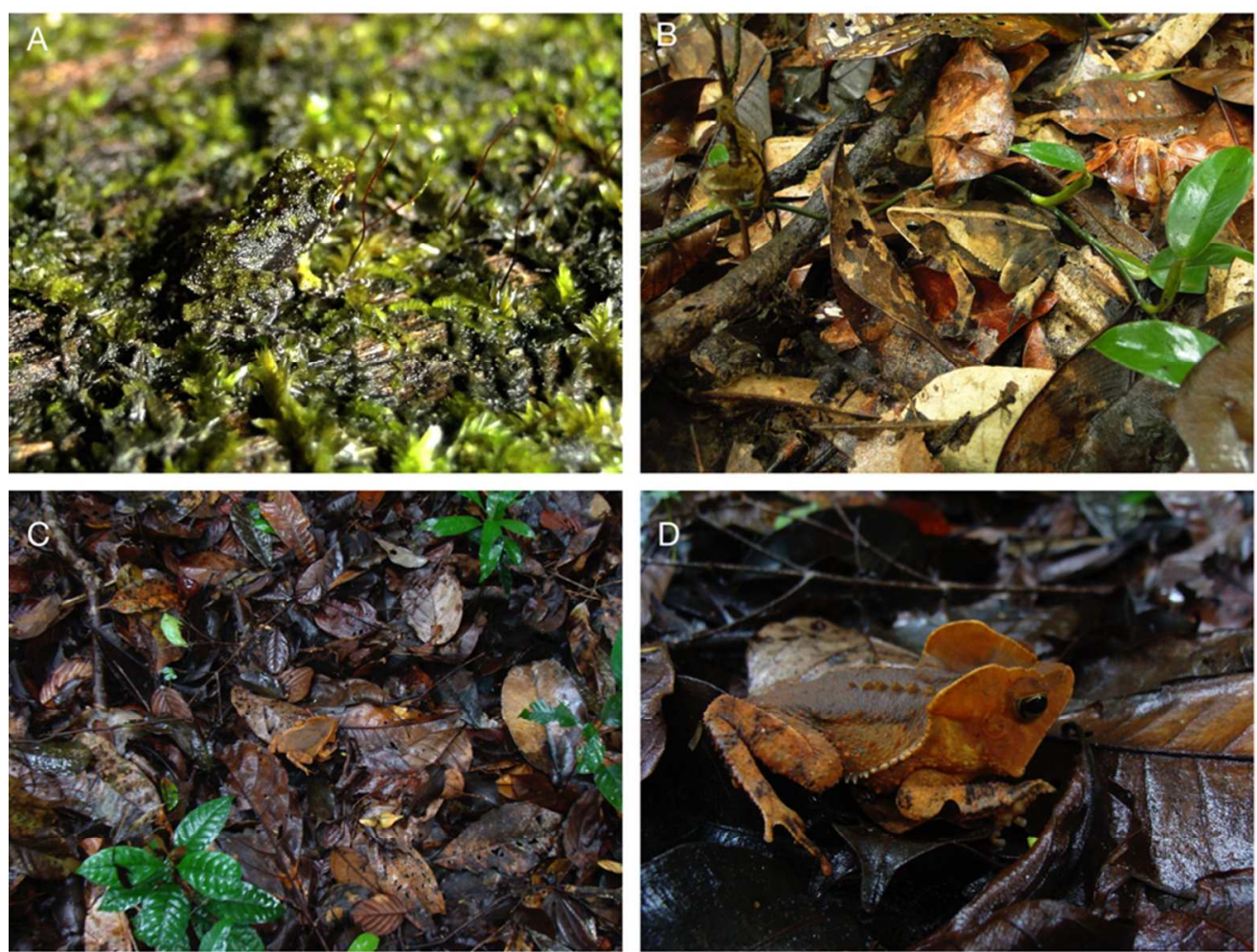

Fig. 1. An example of background matching in a young Pristimantis zeuctotylus (A); and examples of masquerading, where a female Rhinella margaritifera is shown to resemble a dead leaf (B-D). Images $C$ and $\mathrm{D}$ are for the same individual photographed at different distances. Photo credits: Bibiana Rojas. $80 \times 60 \mathrm{~mm}(300 \times 300 \mathrm{DPI})$ 

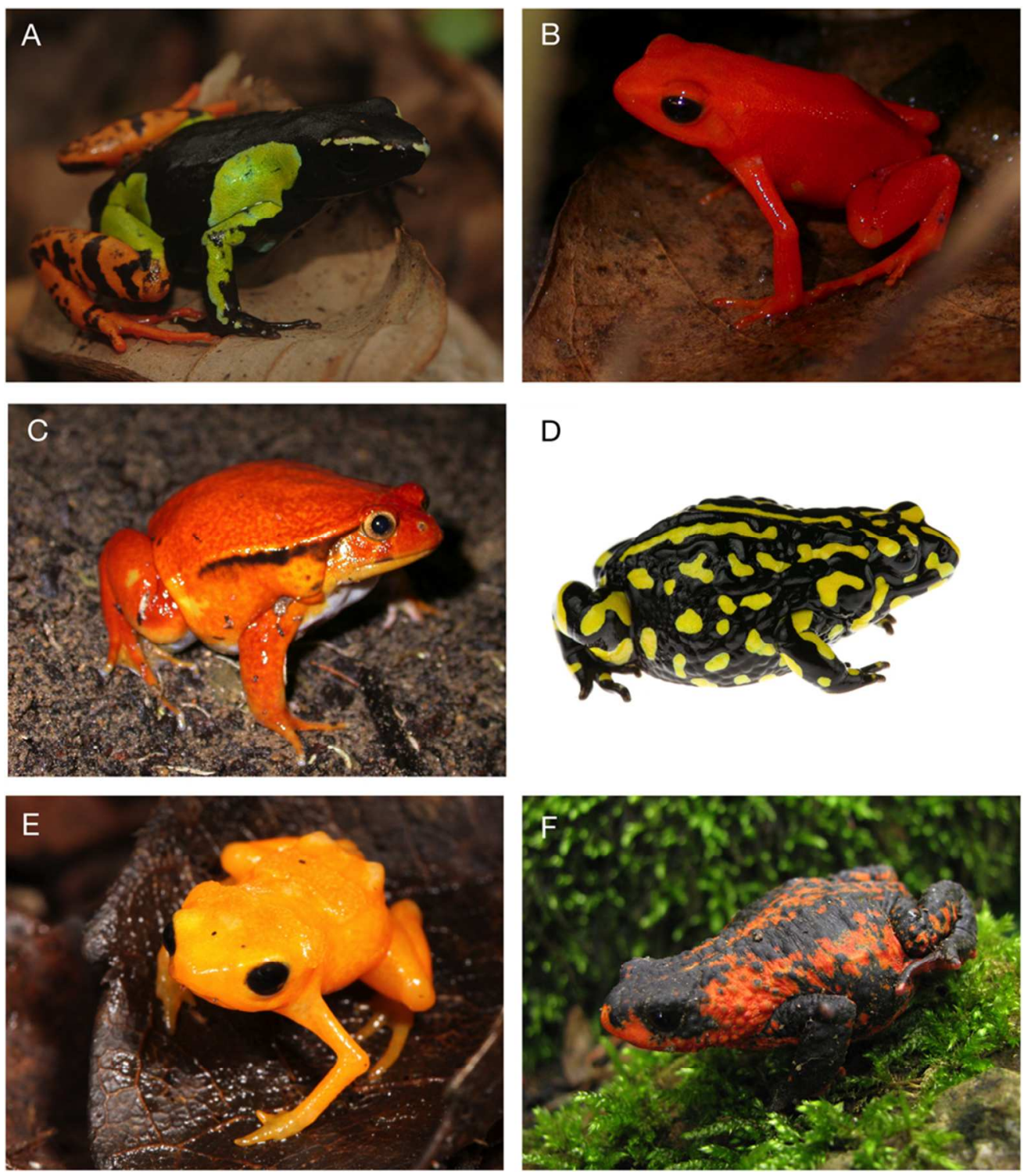

Fig. 2. Aposematic frogs (A) Mantella baroni; (B) Mantella aurantiaca; (C) Dyscophus guineti, known as the 'Tomato frog'; (D) Pseudophryne corroboree; (E) Brachycephalus ephippium; and (F) Melanophryniscus rubriventris. Photo credits: A-C, Gerardo García; D, J.P. Lawrence; E, Taran Grant; F, Marcos Vaira. $80 \times 92 \mathrm{~mm}(300 \times 300 \mathrm{DPI})$ 

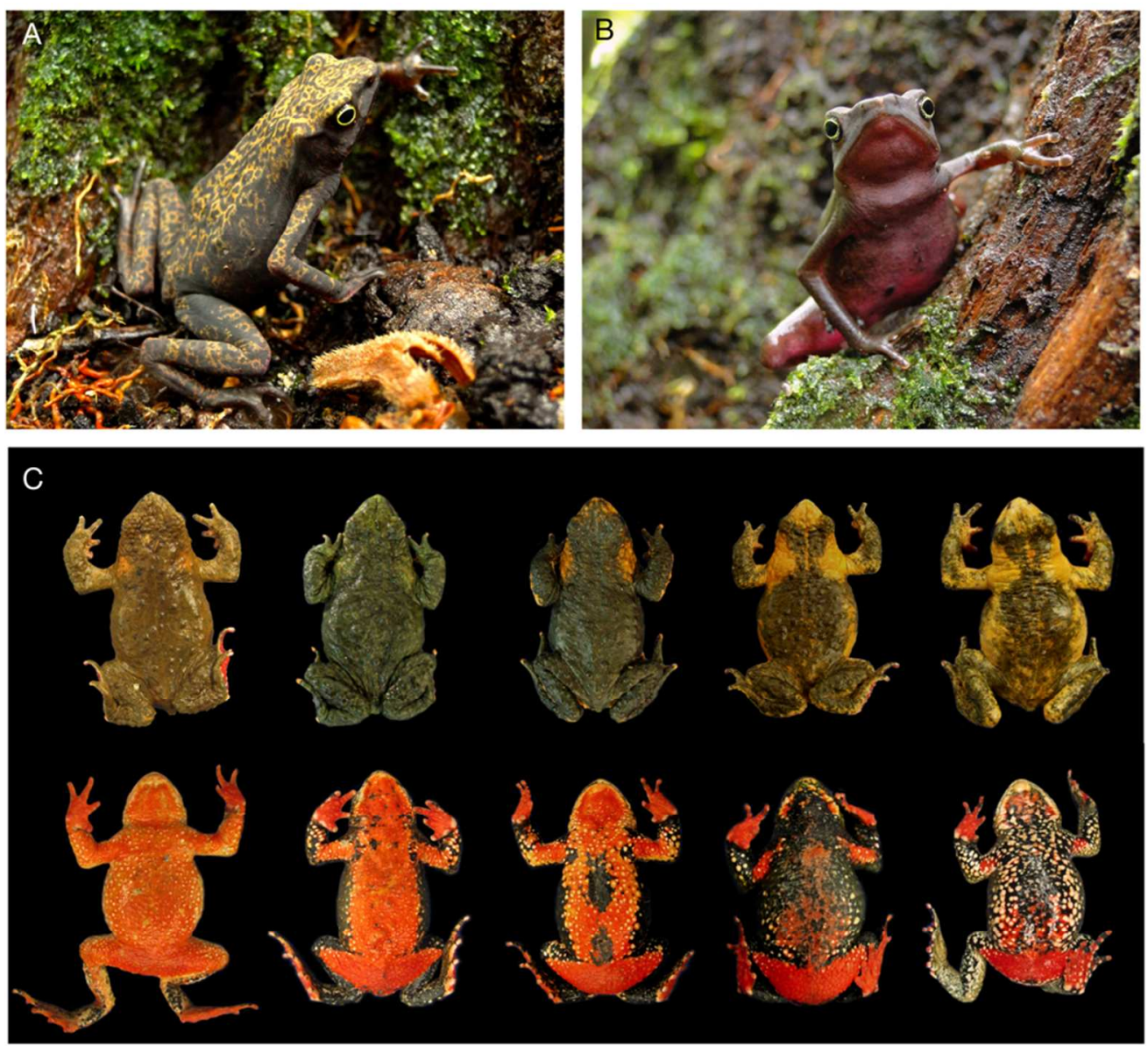

Fig. 3. Atelopus aff. franciscus (A) dorsal and (B) ventral colouration. (C) Geographic variation in the dorsal and ventral colouration of Melanophryniscus rubriventris. Photo credits: A,B, Bibiana Rojas; C, Marcos Vaira. $85 \times 77 \mathrm{~mm}(300 \times 300 \mathrm{DPI})$ 

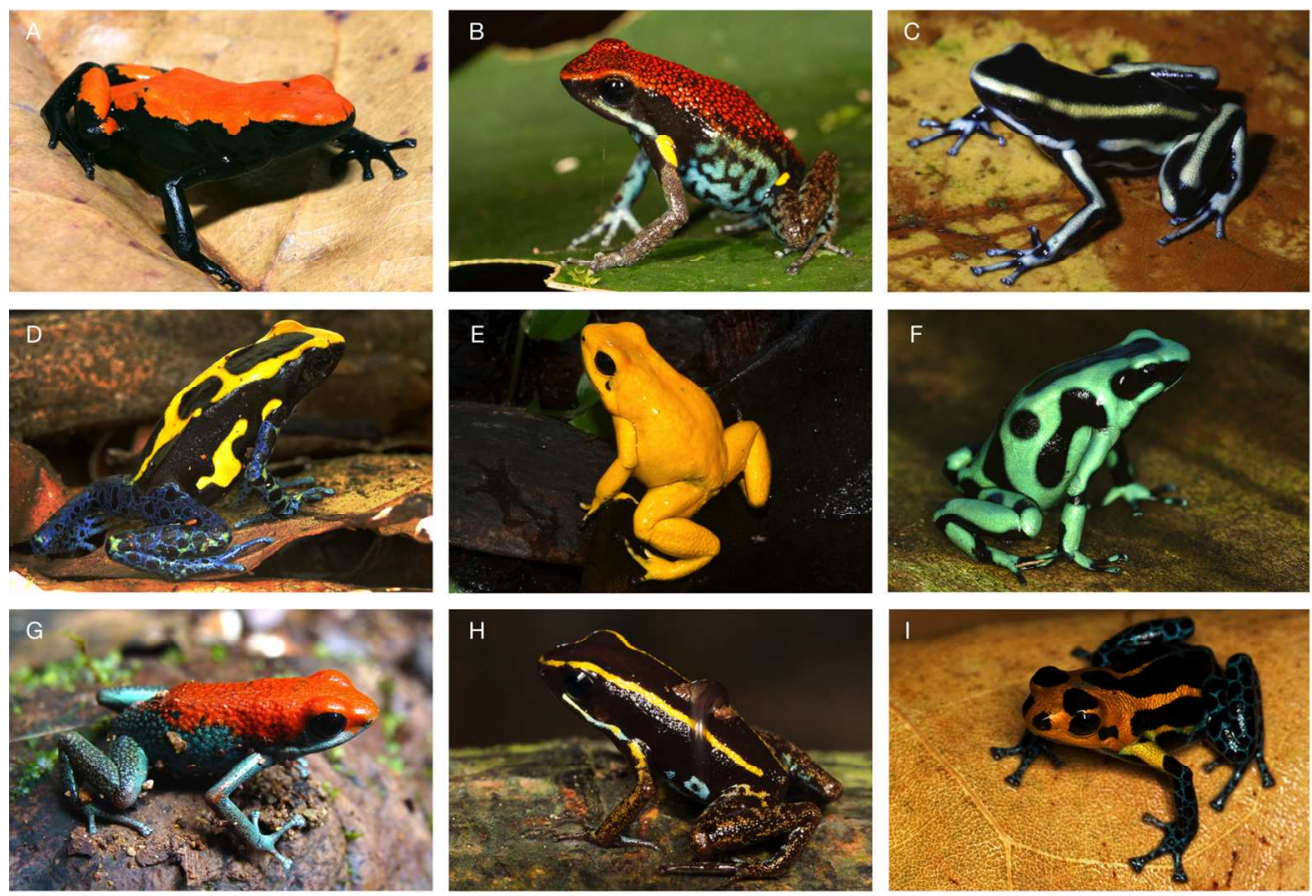

Fig. 4. Dart poison frogs represent the best-known example of aposematism among anurans. (A) Adelphobates galactonotus; (B) Ameerega bilinguis; (C) Dendrobates truncatus; (D) Dendrobates tinctorius;

(E) Phyllobates terribilis; (F) Dendrobates auratus; (G) Oophaga granulifera; (H) Phyllobates lugubris and

(I) Ranitomeya imitator. Photo credits: A,C, Taran Grant; B,F,H,I, J.P. Lawrence; D, G, Bibiana Rojas; E, Roberto Márquez. $129 \times 87 \mathrm{~mm}(300 \times 300 \mathrm{DPI})$ 

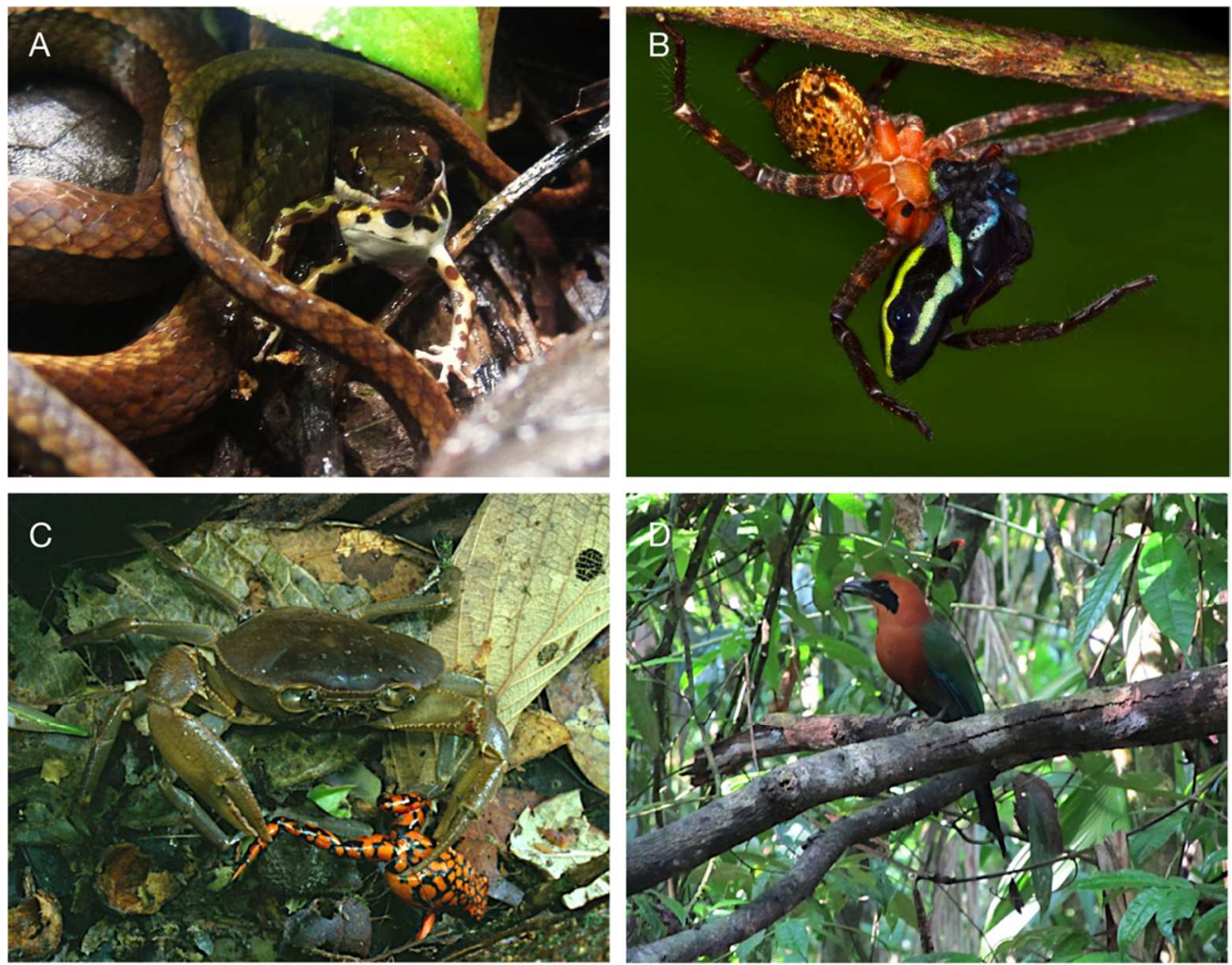

Fig. 5. Known predators of dendrobatid frogs: $(A)$ the snake Rhadinaea decorata, feeding on O. pumilio; (B) wolf spider (Lycosidae) preying on Ameerega trivittata; (C) crab holding an individual Oophaga histrionica;

(D) rufous motmot (Baryphthengus martii) taking an O. pumilio to its nest. Photo credits: A, Matthew Dugas; B, Trond Larsen; C, Alejandro Vélez; D, Ralph Saporito. $104 \times 81 \mathrm{~mm}(300 \times 300$ DPI $)$ 

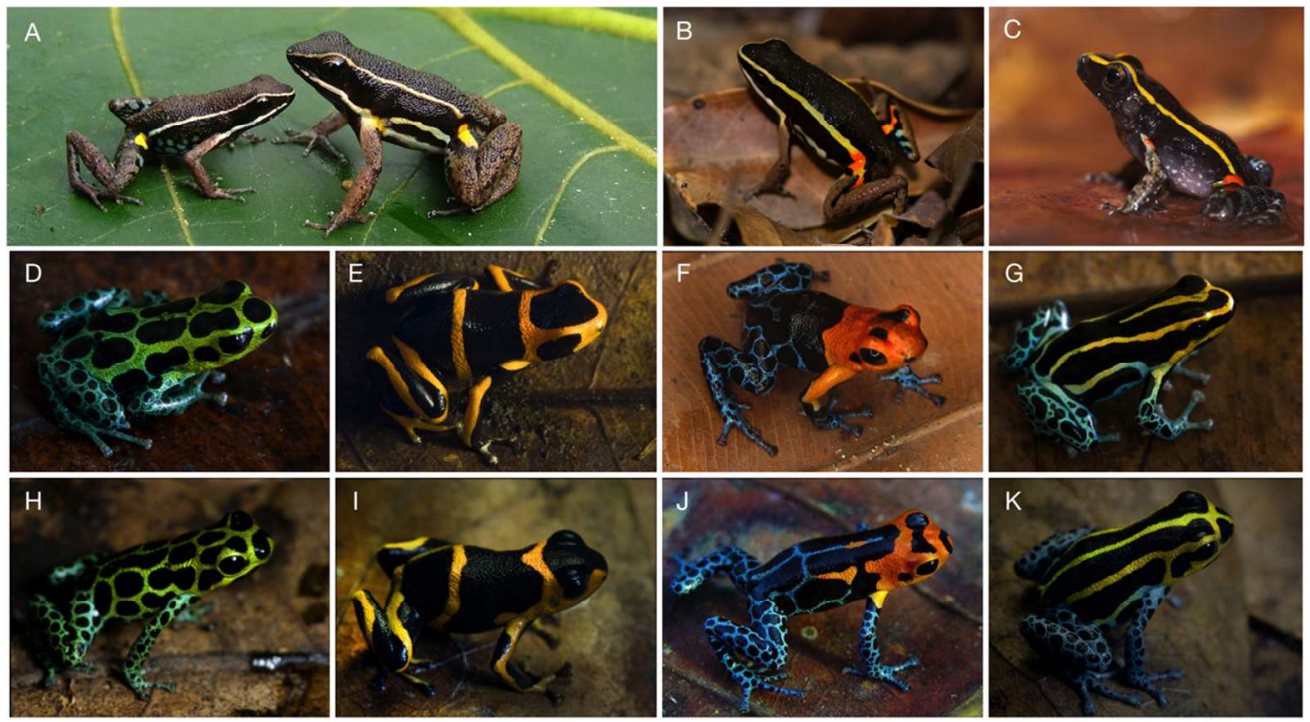

Fig. 6. Examples of mimicry among poison frog species. (A) Ameerega hahneli (left) is thought to be a model for Allobates femoralis (right); Leptodactylus lineatus (C) has been suggested to be a Müllerian mimic of Ameerega picta (B). The best-known case of a Müllerian mimicry system is that of Ranitomeya imitator. D-G are the model species: Ranitomeya variabilis, highland morph; R. summersi, R. fantastica, R. variabilis lowland morph. The different morphs of R. imitator are shown below: (H) spotted; (I) banded; (J) varadero; and (K) striped. Photo credits: A, Jason L. Brown; B, Mauricio Pacheco; C, Quentin Martínez; D-K Evan Twomey.

$107 \times 59 \mathrm{~mm}(300 \times 300$ DPI $)$ 

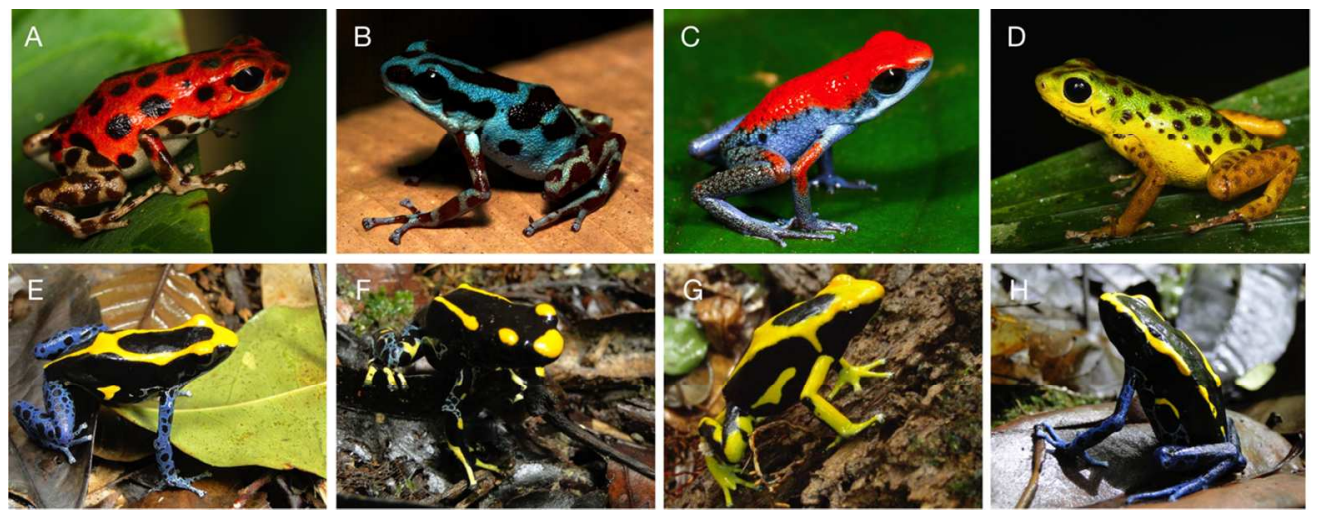

Fig. 7. Examples of geographic variation in the colour patterns of Oophaga pumilio (A-D); and intrapopulation variation in Dendrobates tinctorius $(E-H)$. Photo credits: $A-D$, J.P. Lawrence; $E-H$, Bibiana Rojas.

$119 \times 46 \mathrm{~mm}(300 \times 300 \mathrm{DPI})$ 

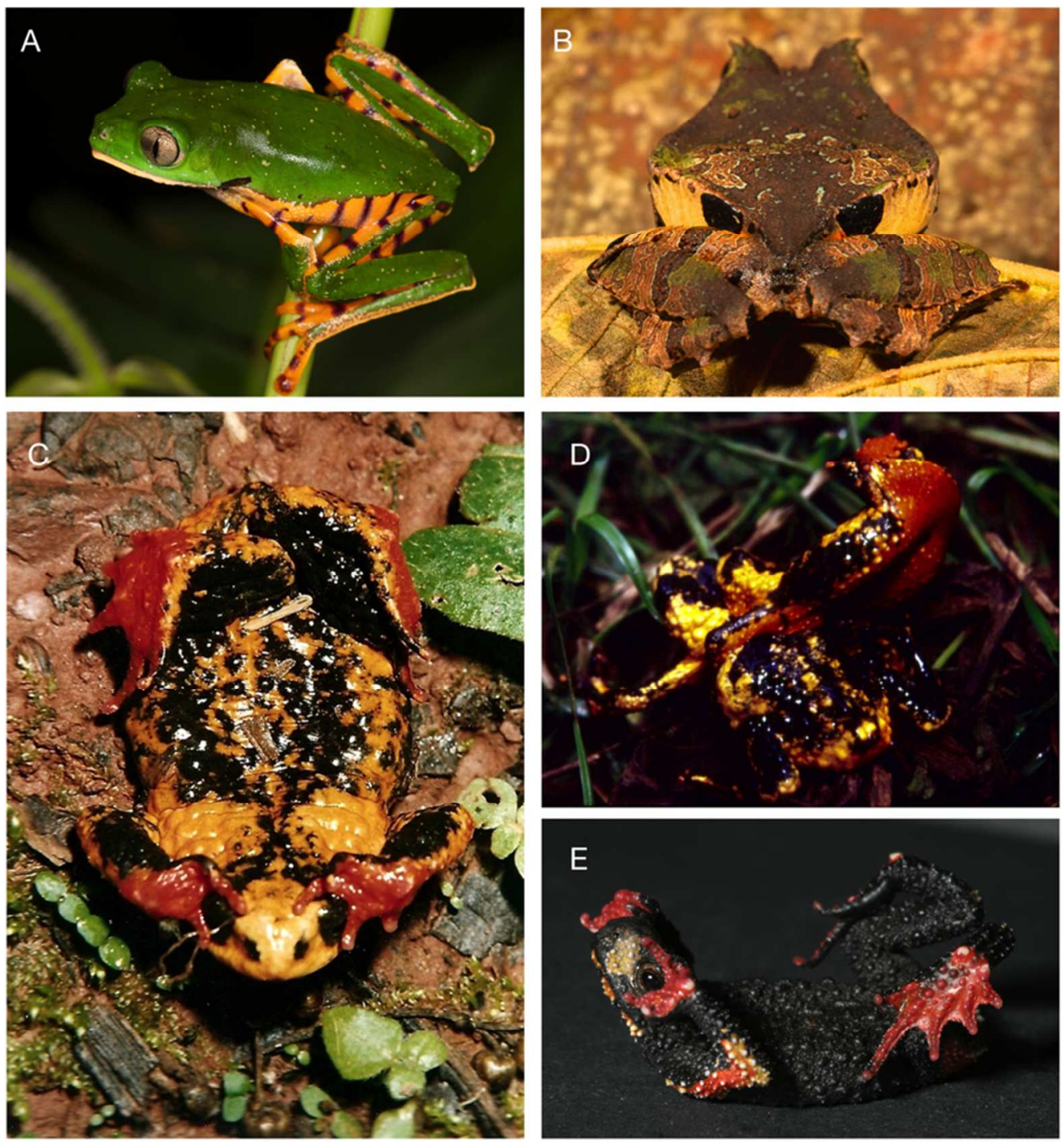

Fig. 8. Flash colouration in the flanks of Phyllomedusa tomopterna (A); 'eye spots' in the lower dorsum of Edalorhina perezi (B); and (C-E) the 'unken reflex' performed by species of the genus Melanophryniscus, even in amplexus (D) . All have been suggested to function as deimatic displays. Photo credits: A, B, J.P. Lawrence; C,D, Marcos Vaira; E, Taran Grant. 

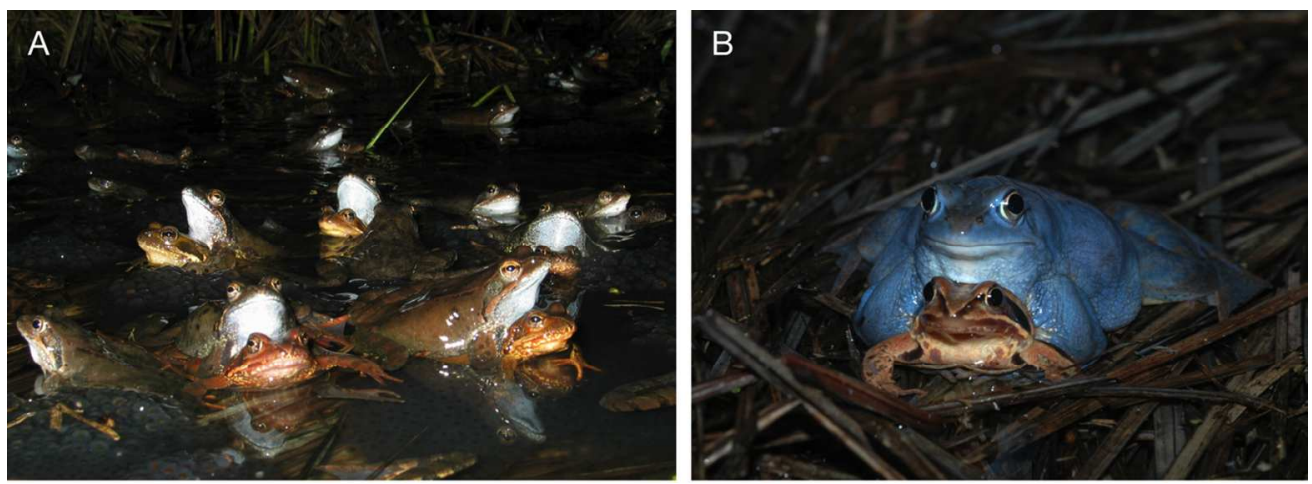

Fig. 9. Breeding aggregation of Rana temporaria (A) and a pair of the moor frog (Rana arvalis) in amplexus (B). Note the bright throats and blue colouration of the males, which are thought to function as sexrecognition cues to prevent mismatings. Photo credits: Marc Sztatecsny. $119 \times 43 \mathrm{~mm}(300 \times 300 \mathrm{DPI})$ 